\title{
IMPACTO DOS INVESTIMENTOS EM TECNOLOGIA DE INFORMAÇÃO NO DESEMPENHO FINANCEIRO DAS INDÚSTRIAS BRASILEIRAS
}

\author{
Luci Longo* \\ luci_plano@yahoo.com.br \\ Fernando De Souza Meirelles ** \\ fernando.meirelles@fgv.br \\ *Universidade Estadual do Centro Oeste do Paraná - Guarapuava, PR / Brasil \\ **Fundação Getúlio Vargas - São Paulo, SP / Brasil \\ http://dx.doi.org/10.1590/1413-2311.0142014.48853 \\ Avaliado pelo sistema "double blind review" \\ Editada pela Escola de Administração da Universidade Federal do Rio Grande do Sul. \\ Sistema requerido: Adobe Acrobat Reader
}

Recebido em 24/04/2014

Aprovado em 16/03/2016

Disponibilizado em 01/07/2016

Revista Eletrônica de Administração

Editora-chefe: Aurora Zen

ISSN 1413-2311 (versão "on line")

Periodicidade: Quadrimestral

\section{RESUMO}

Este artigo é oriundo de pesquisa que buscou aprofundar discussões existentes sobre a avaliação dos investimentos em TI e como aferir o impacto destes sobre o desempenho organizacional. O objetivo consistiu em identificar e analisar os impactos dos gastos e investimentos em tecnologia de informação no desempenho financeiro das indústrias brasileiras. Os resultados obtidos possibilitam afirmar que as indústrias que mais investiram em Tecnologia de Informação (TI), no período de 2001 a 2011, obtiveram maior crescimento da sua receita operacional e resultados operacionais melhores, comparadas com as indústrias que investiram menos no período. Foram adotadas métricas contábeis-financeiras e indicadores de gastos em TI, bem como a combinação de técnicas estatísticas para as análises em diversas etapas do trabalho de tese. O universo da pesquisa foi composto pelas companhias brasileiras, de capital aberto, do ramo industrial, com ações ativas na BOVESPA, totalizando 119 companhias. Por meio de uma survey obteve-se os dados complementares referentes aos gastos e investimentos em TI; os questionários semiestruturados foram encaminhados ao Gerente de TI (Chief Information Officer). Dessa forma, obteve-se uma amostra significativa, com $53 \%$ da população estudada. A pesquisa empírica culminou com a adoção de modelo econométrico dinâmico, estimado pelo Método dos Momentos Generalizado (GMM), satisfazendo as condições do modelo de Arellano-Bond (1991). Este modelo mostrou-se mais adequado para tratar possíveis correlações espúrias, possibilitando identificar que os gastos e investimentos em TI, (IGTI t-2), de dois períodos anteriores impactam no Resultado Operacional Atual, $\left(\mathbf{R O P}_{\mathbf{t}}\right)$, evidenciando o efeito tardio (lag effect). A principal variável de TI da pesquisa, o IGTI, é calculada pela soma de gastos e investimentos em TI anuais (OPEX/CAPEX), dividida pela Receita Operacional Líquida anual. Para pesquisas futuras, há a possibilidade de buscar medidas de avaliação por tipos de 
Luci Longo \& Fernando De Souza Meirelles

investimento em TI, ligado a cada investimento e também poderia ser utilizado dummies de tempo nas regressões, visando mitigar os resultados apurados e possíveis interferências no desempenho.

Palavras-Chave: Tecnologia de informação (TI); Investimentos em TI; Impacto dos Investimentos em TI; Custo de TI.

\title{
IMPACT OF INFORMATION TECHNOLOGY INVESTMENT IN THE FINANCIAL PERFORMANCE OF BRAZILIAN INDUSTRY
}

\begin{abstract}
This article comes from research that sought to deepen existing discussions on the evaluation of IT investments and to assess their impact on organizational performance. The goal was to identify and analyze the impacts of spending and investments in information technology in the financial performance of Brazilian industries. The results allowed to state that the industries that have invested in Information Technology (IT), from 2001 to 2011, had higher growth of its operating revenue and improved operating results compared to the industries that invested less in the period. We adopted a research model that used accounting and financial indicators and IT spending metrics, also the combination of statistical techniques for analysis in several of doing thesis work. The study population was composed of Brazilian companies, which were publicly traded, from the industrial sector, with active stocks at BOVESPA, totaling 119 companies. Through a survey, additional data were obtained related to expenditures and investments in IT, the semi-structured questionnaires were sent directly to the Chief Information Officer (CIO). These efforts in collecting data, gave the possibility of obtaining a significant sample, with $53 \%$ of the population. Empirical research culminated with the adoption by the Generalized Method of Moments (GMM), a dynamic econometric model, satisfying the requirements of the Arellano-Bond (1991) model. This model was more suitable to treat possible spurious correlations; allowing identify the cost/expenditures and IT investments in two previous periods, $\left(\mathbf{I G T I}_{\mathbf{t}-2}\right)$ impacted in current Operating Income $\left(\mathbf{R O P} \mathbf{P}_{\mathbf{t}}\right)$, reflecting the lag effect. The main variable of IT research, IGTI is calculated through the sum of expenditures and annual IT investments (OPEX/CAPEX), divided by the annual net Operating Revenue. For future research, there is the possibility of seeking measures of evaluation by types of IT investment, linked to each investment and could also be used time dummies in the regressions, to mitigate the confirmed results and potential interference with the performance.
\end{abstract}

Keywords: Information Technology (IT); IT investments; Impact of IT investments; Cost of IT.

REAd | Porto Alegre - Edição 83 - № 1 - janeiro/abril 2016 - p. 134-165 


\title{
IMPACTO DOS INVESTIMENTOS EM TECNOLOGIA DE INFORMAÇÃO NO DESEMPENHO FINANCEIRO DAS INDÚSTRIAS BRASILEIRAS
}

\section{IMPACTO DE LAS TECNOLOGÍAS DE LA INFORMACIÓN DE INVERSIÓN EN EL DESEMPEÑO FINANCIERO DE LA INDUSTRIA BRASILEÑA}

\begin{abstract}
RESUMEN
Este artículo proviene de una investigación que buscó profundizar las discusiones existentes sobre la evaluación de las inversiones en TI y para evaluar su impacto en el rendimiento de la organización. El objetivo fue identificar y analizar el impacto del gasto y las inversiones en tecnología de la información en el desempeño financiero de las industrias brasileñas. Los resultados permitieron establecer que las industrias que han invertido en tecnología de la información (IT), de 2001 a 2011, tuvieron un mayor crecimiento de los ingresos de explotación y la mejora de los resultados operativos en comparación con las industrias que invierten menos en el período. métricas e indicadores en el gasto de TI contables y financieras se adoptaron, y la combinación de técnicas estadísticas para el análisis en varias etapas del trabajo de tesis. El universo de la investigación fue compuesta por empresas brasileñas, que cotiza en bolsa, el sector industrial, con participaciones activas en Bovespa, por un total de 119 empresas. A través de una encuesta se obtuvieron datos adicionales relativos a los gastos y las inversiones en TI; los cuestionarios semi-estructurados fueron enviados al Director de TI (Director de Información). De este modo, se obtuvo una muestra significativa, con un 53\% de la población estudiada. La investigación empírica culminó con la adopción del modelo econométrico dinámico estimada por el método generalizado de momentos (GMM), que cumpla los requisitos de los Arellano-Bond (1991) modelo. Este modelo era más adecuado para tratar las posibles correlaciones espurias, lo que permite identificar los gastos e inversiones en TI (IGTI t-2), dos periodos anteriores de impacto sobre el rendimiento operativo actual (Ropt), que reflejan el efecto retardado (lag efecto). La principal variable de la investigación de TI, IGTI, se calcula mediante la suma de los gastos anuales de TI y las inversiones (OPEX / CAPEX) dividido por los ingresos operativos netos anuales. Para futuras investigaciones, existe la posibilidad de solicitar medidas de evaluación por tipos de inversión en TI, vinculados a cada inversión y también se podría utilizar dummies de tiempo en las regresiones, para mitigar los resultados confirmados y posibles interferencias con el rendimiento.
\end{abstract}

Palabras-clave: Tecnología de la información (IT); Las inversiones en TI; Impacto de las inversiones de TI; Costos de TI.

\section{INTRODUÇÃO}

Os sistemas e as tecnologias de informação, incluindo sistemas de informação com base na internet têm papel vital e crescente na administração, portanto, um ingrediente indispensável para o sucesso dos negócios (O’BRIEN; MARAKAS, 2013).

Os gastos e investimentos em Tecnologia de Informação (TI) podem incluir uma vasta lista de itens físicos, tais como: equipamentos, assistentes digitais pessoais - e até mesmo

REAd | Porto Alegre - Edição 83 - N 1 - janeiro/abril 2016 - p. 134-165 
Luci Longo \& Fernando De Souza Meirelles

iPods, se usados para fins organizacionais - e também instalações, suprimentos (materiais de consumo), arquitetura de redes, telecomunicação e outros componentes de infraestrutura necessários para o funcionamento da TI; também itens não corpóreos que podem absorver tanto quanto ou mais recursos da organização, tais como: software, serviços, treinamento de pessoal próprio e de terceiros, suporte técnico, estabelecimento de processos, modelos de gestão, serviços de armazenagem e segurança dos dados e demais serviços internos ou terceirizados (WEILL, 1992; MEIRELLES, 1988, 2008; LAUDAON; LAUDON, 2009).

Para esta pesquisa os Gastos e Investimentos em Tecnologia de Informação (IGTI) termo de pesquisa de Longo (2014), bem como o respectivo Índice G incluíram as despesas e capital investido em TI, ou seja, Operational Expenditure (OPEX) e Capital Expenditure (CAPEX).

Cada vez mais a TI torna-se um recurso essencial e um fator crítico de sucesso para as organizações (com custo relevante). Os gastos com TI geralmente variam entre 1\% a 3\% da receita anual e podem chegar até 5 a 10\%, ou acima dependendo da atividade da organização (MEIRELLES, 2015).

Os benefícios potenciais e as reconfigurações induzidas pela TI devem resultar em benefícios efetivos para o negócio (ALBERTIN; ALBERTIN, 2009).

Converter tais investimentos em resultados para o desempenho financeiro das organizações permanece, atualmente, como uma das grandes preocupações dos profissionais de TI, dos gestores e de pesquisadores (HU; PLANT, 2001; KOHLI; DEVARAJ, 2003; LIM; DEHNING; RICHARDSON; SMITH, 2011; LUNARDI; BECKER; MAÇADA, 2012; KOHLI; DEVARAJ; OW, 2012).

A conversão ou efetividade da TI significa a obtenção de benefícios de TI (em decorrência dos esforços e investimentos em TI) e que resultem em melhoria dos indicadores de desempenho organizacional (WEILL, 1992; KOHLI; GROVER, 2008; MITHAS; TAFTI; BARDHAN; GOH, 2012).

Há na literatura de TI e em vários contextos, discussões sobre a adequação de instrumentos que permitam a avaliação dos investimentos em TI e como aferir o seu impacto no desempenho empresarial (HITT; BRYNJOLFSSON, 1996; HU; PLANT, 2001; IRANI; LOVE, 2002; WEILL; ROSS, 2004; MAHMOOD; MANN, 2005; REMENYI;

REAd | Porto Alegre - Edição 83 - N 1 - janeiro/abril 2016 - p. 134-165 


\section{IMPACTO DOS INVESTIMENTOS EM TECNOLOGIA DE INFORMAÇÃO NO DESEMPENHO FINANCEIRO DAS INDÚSTRIAS BRASILEIRAS}

BANNISTER; MONEY, 2007; CARCARY, 2008; LIM; DEHNING; RICHARDSON; SMITH, 2011).

Pesquisas de Hu e Plant (2001), de Maçada, Becker e Lunardi (2005), de Gartner, Zwicker e Rodder (2009) foram importantes no processo de nossa pesquisa, bem como de $\mathrm{Hu}$ e Plant (2001); Mahmood e Mann (2005); Lee e Kim (2006) que discutem as metodologias para mitigar esta relação. Destacou-se ainda, diversas pesquisas que utilizam variáveis (métricas) contábeis-financeiras e de mercado para identificar o desempenho organizacional.

Logo, para esta pesquisa adotou-se indicadores financeiros e de TI com análise de dados em painel para o período, visando atender ao objetivo geral do trabalho de identificar os impactos dos gastos e investimentos em tecnologia de informação (GITI) no desempenho financeiro das indústrias brasileiras.

\section{FUNDAMENTAÇÃO TEÓRICA E DISCUSSÕES}

\subsection{Análise do Impacto dos Gastos e Investimentos em TI}

O real impacto da TI pode permanecer desconhecido e seu potencial não realizado, sendo que são frequentes, na literatura, relatos de projetos fracassados, custos não identificados, benefícios não obtidos, orçamentos não atendidos, retorno limitado de investimentos, ou negativo, além de discrepâncias entre o esperado e o realizado (STRASSMANN, 1997; TINGLING; PARENT, 2004; REMENYI; BANNISTER; MONEY, 2007; CARCARY, 2008).

O fracasso de um projeto de grande monta pode ter consequências sérias, inclusive comprometendo a continuidade da organização (REMENYI, 1999; BANNISTER, McCABE; REMENYI, 2002; REMENYI; GRIFFITHS; DINIZ, 2004). E, tanto excesso, quanto falta de investimentos, podem acabar comprometendo a estrutura e o funcionamento da empresa (LUNARDI; BECKER; MAÇADA, 2012).

Pesquisas e estatísticas de TI revelam que mais de $70 \%$ dos projetos foram tumultuados, seja por exceder o prazo, seja por não funcionar como previsto, ou ainda por absorver grandes quantidades de recursos, mas sem oferecer os benefícios prometidos (PAN; PAN; FLYNN, 2004; AL-SHEHAB; HUGHES; WINSTANLEY, 2005; FLYVBJERG; BUDZIER, 2011).

REAd | Porto Alegre - Edição 83 - N 1 - janeiro/abril 2016 - p. 134-165 
Luci Longo \& Fernando De Souza Meirelles

Segundo Maizlish e Handler (2005) e Lunardi et al. (2012), 72\% dos projetos de TI são entregues com atraso, ultrapassam seu orçamento, apresentam falta de funcionalidade ou nunca são entregues. Destes $28 \%$ de projetos considerados bem sucedido, $45 \%$ ultrapassam o orçamento e $68 \%$ levam mais tempo que o planejado, dessa forma, metade dos executivos declararam estar insatisfeitos quanto aos custos utilizados e apenas 52\% dos projetos concluídos obtêm valor estratégico, o que significa que, somente investir em TI, não representa uma garantia de ganhos para o negócio.

\subsection{Medidas Contábeis e de Mercado para Análise da Conversão da TI}

Os pesquisadores da área de TI têm feito progressos significativos especialmente relacionados à análise do valor da TI e às capacidades para o desempenho da empresa (MITHAS; TAFTI; BARDHAN; GOH, 2012; KOHLI; GROVER, 2008; LIM; DEHNING; RICHARDSON; SMITH, 2011).

Em comparação com o corpo de pesquisa da literatura sobre o valor de TI, a literatura sobre sistemas e gestão de informação (TI/MIS) - Accounting Information Systems (AIS) é muito menos extensa, mas este campo de literatura vem se destacando, com boas contribuições (DEHNING; RICHARDSON, 2002; MASLI; RICHARDSON; SANCHEZ; SMITH, 2011; LIM; DEHNING; RICHARDSON; SMITH, 2011).

Lim, Dehning, Richardson e Smith (2011) apresentam uma meta-análise voltada às pesquisas relevantes sobre os impactos dos investimentos em TI no desempenho financeiro da empresa. Os autores categorizaram as medidas de desempenho financeiro com base no mercado, ou com base na contabilidade, destacando suas características.

O principal argumento para uso de medidas de mercado consiste na vantagem teórica, por representarem melhor os benefícios futuros esperados do investimento em TI. Por outro lado, medidas de mercado são medidas amplas de desempenho, facilmente confundidas com outros fatores, como diferenças de risco, as mudanças na competição e as mudanças no ambiente da informação. Sendo assim, os estudos que examinaram os gastos de TI são mais propensos a encontrar evidências do impacto sobre o desempenho em medidas baseadas em contabilidade (LIM; DEHNING; RICHARDSON; SMITH, 2011).

REAd | Porto Alegre - Edição 83 - Nº 1 - janeiro/abril 2016 - p. 134-165 


\section{IMPACTO DOS INVESTIMENTOS EM TECNOLOGIA DE INFORMAÇÃO NO DESEMPENHO FINANCEIRO DAS INDÚSTRIAS BRASILEIRAS}

Também Masli, Richardson, Sanchez e Smith (2011) apontam que, no nível da empresa, as informações contábeis são amplamente disponíveis e, assim, pesquisas vêm utilizando uma variedade de métricas contábeis.

Alguns trabalhos mostraram que existe correlação serial forte em medidas contábeis, que o pesquisador deve levar em conta ao medir o desempenho atual ou o desempenho futuro (HU; PLANT, 2001; DEHNING; RICHARDSON; ZMUD, 2007; MASLI; RICHARDSON; SANCHEZ; SMITH, 2011).

De qualquer forma, em pesquisas para compreender as potenciais contribuições do investimento em TI para o desempenho financeiro, deve-se reconhecer que as métricas contábeis, ao nível da empresa são medidas de resumo (MASLI; RICHARDSON; SANCHEZ; SMITH, 2011). E, sempre que possível, os pesquisadores devem analisar medidas mais específicas de desempenho do processo, tais como o giro de estoque e mudanças de despesas (DEHNING; RICHARDSON; ZMUD, 2007; MASLI; RICHARDSON; PETERS, 2010; MASLI; RICHARDSON; SANCHEZ; SMITH, 2011; LIM; DEHNING; RICHARDSON; SMITH, 2011).

\subsection{Pesquisas Selecionadas com enfoque em Métricas Contábeis}

Conforme Tabela 1, contendo as abordagens, as variáveis adotadas e os resultados obtidos em diferentes épocas, observa-se que os pesquisadores tendem a utilizar dados anuais para os gastos de TI e medidas contábeis-financeiras, especialmente indicadores de rentabilidade e lucratividade (HITT; BRYNJOLFSSON, 1996; DEVARAJ; KOHLI, 2000; PARENTE; VAN HORN, 2007; ARAL; WEILL, 2007; SHIN, 2006; NICOLAOU, 2004; MENON; LEE; ELDENBURG, 2000; MITHAS; TAFTI; BARDHAN; GOH, 2012).

Há pesquisadores que preferem adotar a associação de métricas contábeis e de mercado; nestas pesquisas, em geral, relacionam os indicadores de TI, margens internas e indicadores do mercado de ações (HU; PLANT, 2001; ANDERSON; BANKER; RAVINDRAN, 2006; HENDERSON; KOBELSKY; RICHARDSON; SMITH, 2010; DUNN; KOHLBECK; MAGILKE, 2009; KOBELSKY; RICHARDSON; SMITH; ZMUD, 2008; KOHLI; DEVARAJ; OW, 2012).

REAd | Porto Alegre - Edição 83 - N 1 - janeiro/abril 2016 - p. 134-165 


\section{Luci Longo \& Fernando De Souza Meirelles}

Tabela 1 - Síntese de pesquisas com métricas contábeis e de mercado

\begin{tabular}{|c|c|c|c|c|c|}
\hline Pesquisa & $\begin{array}{l}\text { Abordagem } \\
\text { Analítica } \\
\end{array}$ & $\begin{array}{l}\text { Tipo de } \\
\text { Medida }\end{array}$ & $\begin{array}{l}\text { Variáveis de TI e de } \\
\text { Desempenho }\end{array}$ & $\begin{array}{l}\text { Variável de } \\
\text { Desempenho } \\
\end{array}$ & $\begin{array}{l}\text { Síntese do Resultado (pontos- } \\
\text { chave) }\end{array}$ \\
\hline $\begin{array}{l}\text { Kohli et al. } \\
\text { (2012) }\end{array}$ & Regressão & $\begin{array}{l}\text { De } \\
\text { Mercado, } \\
\text { Contábil e } \\
\text { Operacional }\end{array}$ & $\begin{array}{l}\text { Investimento em TI; } \\
\text { Valor de mercado dos } \\
\text { ativos; } \\
\text { Ativos totais (AT) - } \\
\text { valor de book; } \\
\text { Retorno sobre ativos } \\
\text { (ROA); } \\
\text { Receita líquida total; } \\
\text { Idade do hospital e } \\
\text { outras variáveis } \\
\text { (ocupação, serviços } \\
\text { hospitalares). }\end{array}$ & $\begin{array}{l}\text { Lucro } \\
\text { operacional } \\
\text { (EBITDA) } \\
\text { Relação Valor } \\
\text { de Mercado } \\
\text { (Ativo Total) e } \\
\text { Valor de Ativo } \\
\text { (contábil) }\end{array}$ & $\begin{array}{l}\text { A influência do investimento em } \\
\text { TI na empresa é mais significativa } \\
\text { estatisticamente no valor da } \\
\text { empresa. } \\
\text { O impacto do investimento em TI } \\
\text { não ficou evidenciado no retorno } \\
\text { sobre ativos (ROA) e lucro } \\
\text { operacional para o conjunto de } \\
\text { hospitais. O impacto global de TI } \\
\text { é melhor compreendido com } \\
\text { medidas contábeis combinadas } \\
\text { com de mercado. }\end{array}$ \\
\hline $\begin{array}{l}\text { Mithas et al. } \\
\text { (2012) }\end{array}$ & $\begin{array}{l}\text { Regressão } \\
\text { em painel }\end{array}$ & Contábil & $\begin{array}{l}\text { Orçamento anual de } \\
\text { TI, despesas } \\
\text { operacionais, } \\
\text { receitas (vendas), } \\
\text { gastos com pesquisa e } \\
\text { desenvolvimento } \\
\text { (R\&D), gastos da } \\
\text { indústria (razão } \\
\text { capital-indústria). } \\
\end{array}$ & Lucro Líquido & $\begin{array}{l}\text { TI tem um impacto positivo na } \\
\text { rentabilidade. } \\
\text { O efeito dos investimentos em TI } \\
\text { sobre vendas e rentabilidade é } \\
\text { maior do que a de outros } \\
\text { Investimentos discricionários (em } \\
\text { publicidade discricionária e } \\
\text { Gastos em pesquisas } \\
\text { desenvolvimento (R\&D). }\end{array}$ \\
\hline $\begin{array}{l}\text { Henderson et } \\
\text { al. (2010) }\end{array}$ & Regressão & $\begin{array}{l}\text { De Mercado } \\
\text { e Contábil }\end{array}$ & $\begin{array}{l}\text { Despesas (gastos) } \\
\text { com TI, Gastos com } \\
\text { Pesquisa e } \\
\text { Desenvolvimento } \\
\text { (R\&D), Gastos em } \\
\text { publicidade, } \\
\text { Investimentos de } \\
\text { capital. }\end{array}$ & $\begin{array}{l}\text { Valor de } \\
\text { mercado, Valor } \\
\text { contábil } \\
\text { registrado (book } \\
\text { value) e } \\
\text { ganhos. }\end{array}$ & $\begin{array}{l}\text { Gastos de TI podem explicar o } \\
\text { desempenho futuro. } \\
\text { A falta de informação confiável } \\
\text { de gastos com TI pode levar a } \\
\text { preços incorretos de mercado. }\end{array}$ \\
\hline $\begin{array}{l}\text { Dunn et al. } \\
\text { (2009) }\end{array}$ & Regressão & $\begin{array}{l}\text { De Mercado } \\
\text { e } \\
\text { Contábil }\end{array}$ & $\begin{array}{l}\text { Offshoring }{ }^{I} \text { de TI } \\
\text { (empregos) }\end{array}$ & $\begin{array}{l}\text { O retorno sobre } \\
\text { os ativos } \\
\text { (ROA), } \\
\text { Fluxo de caixa } \\
\text { operacional e } \\
\text { valor de } \\
\text { mercado. }\end{array}$ & $\begin{array}{l}\text { As empresas relatam maiores } \\
\text { ganhos e fluxos de caixa } \\
\text { operacionais na sequência de um } \\
\text { offshoring de TI; } \\
\text { O mercado desconta offshoring de } \\
\text { TI, mas o desconto é reduzido, o } \\
\text { número relativo de empregos } \\
\text { deslocados (transferidos) } \\
\text { aumenta. }\end{array}$ \\
\hline $\begin{array}{l}\text { Kobelsky et } \\
\text { al. (2008) }\end{array}$ & Regressão & $\begin{array}{l}\text { De Mercado } \\
\text { e Contábil }\end{array}$ & $\begin{array}{l}\text { Nível de orçamento } \\
\text { de TI }\end{array}$ & $\begin{array}{l}\text { Retorno } \\
\text { operacional } \\
\text { sobre vendas } \\
\text { (ROS), retorno } \\
\text { sobre } \\
\text { ativos (ROA); } \\
\text { desempenho das } \\
\text { ações. }\end{array}$ & $\begin{array}{l}\text { Níveis de TI orçados pode } \\
\text { influenciar ambos o desempenho } \\
\text { da empresa e o retorno para o } \\
\text { acionista. } \\
\text { No contexto o orçamento de TI } \\
\text { proporciona orientação; e níveis } \\
\text { idiossincráticos (específicos) têm } \\
\text { diferentes impactos. }\end{array}$ \\
\hline $\begin{array}{l}\text { Parente e } \\
\text { Van Horn } \\
(2007)\end{array}$ & $\begin{array}{l}\text { Regressão } \\
\text { Logística }\end{array}$ & Contábil & $\begin{array}{l}\text { Mandato de TI } \\
\text { (posse), total de } \\
\text { custos de ativos, } \\
\text { volume (leitos, } \\
\text { desocupação, dias de } \\
\text { internação). }\end{array}$ & $\begin{array}{l}\text { Retorno } \\
\text { operacional } \\
\text { sobre ativos } \\
\text { (ROA) }\end{array}$ & $\begin{array}{l}\text { Encontram o efeito marginal da } \\
\text { adoção de TI em atividades com } \\
\text { fins lucrativos. } \\
\text { Na produtividade - efeito nos } \\
\text { custos; em atividades em } \\
\text { hospitais sem fins lucrativos - }\end{array}$ \\
\hline
\end{tabular}

1 Offshoring de TI - Realocação de serviços de um país desenvolvido para outro em desenvolvimento (países emergentes), onde seja possível encontrar profissionais com qualificação técnica similar, porém a um custo reduzido.

REAd | Porto Alegre - Edição 83 - № 1 - janeiro/abril 2016 - p. 134-165 


\section{IMPACTO DOS INVESTIMENTOS EM TECNOLOGIA DE INFORMAÇÃO NO DESEMPENHO FINANCEIRO DAS INDÚSTRIAS BRASILEIRAS}

\begin{tabular}{|c|c|c|c|c|c|}
\hline & & & & & $\begin{array}{l}\text { aumentam os serviços prestados } \\
\text { (volume de atendimento). }\end{array}$ \\
\hline $\begin{array}{l}\text { Aral e Weill } \\
(2007)\end{array}$ & $\begin{array}{l}\text { Regressão - } \\
\text { Modelo de } \\
\text { efeitos fixos }\end{array}$ & Contábil & $\begin{array}{l}\text { Gastos com TI e } \\
\text { ativos de TI - } \\
\text { Infraestrutura, } \\
\text { transacional, } \\
\text { Informacional e } \\
\text { Estratégico. }\end{array}$ & $\begin{array}{l}\text { Retorno sobre } \\
\text { ativos (ROA), } \\
\text { Margem } \\
\text { Líquida, } \\
\text { Q de Tobin, o } \\
\text { CPV e } \\
\text { Receita } \\
\text { Produtos novos }\end{array}$ & $\begin{array}{l}\text { Investimento em ativos } \\
\text { específicos de TI explica } \\
\text { Diferenças de desempenho. }\end{array}$ \\
\hline $\begin{array}{l}\text { Anderson et } \\
\text { al. }(2006)\end{array}$ & $\begin{array}{l}\text { Regressão - } \\
\text { Mínimos } \\
\text { Quadrados } \\
\text { Ordinários } \\
\text { (MQO) }\end{array}$ & $\begin{array}{l}\text { De Mercado } \\
\text { e Contábil }\end{array}$ & $\begin{array}{l}\text { Gastos relacionados } \\
\text { ao Bug do milênio } \\
\text { (Y2K), } \\
\text { Lucros, Pesquisa e } \\
\text { Desenvolvimento } \\
\text { (P\&D), crescimento } \\
\text { de vendas e } \\
\text { crescimento dos } \\
\text { ativos. }\end{array}$ & $\begin{array}{l}\text { Proporção do } \\
\text { valor de } \\
\text { mercado e valor } \\
\text { de book } \\
\text { (contábil) }\end{array}$ & $\begin{array}{l}\text { Gastos relacionados com TI } \\
\text { gastos da passagem de milênio } \\
\text { (Y2K) aumentou o valor da } \\
\text { empresa nas indústrias onde a TI } \\
\text { desempenha um papel } \\
\text { transformador. }\end{array}$ \\
\hline Shin (2006) & Regressão & Contábil & $\begin{array}{l}\text { Gastos de TI } \\
\text { (orçamento), Retorno } \\
\text { sobre Ativos (ROA) e } \\
\text { Retorno sobre PL } \\
\text { (ROE). }\end{array}$ & Margem Bruta & $\begin{array}{l}\text { Orçamento de TI e sua interação } \\
\text { com a direção estratégica. } \\
\text { A questão da interação de TI e de } \\
\text { direção estratégica contribui para } \\
\text { o desempenho financeiro, } \\
\text { particularmente na margem bruta. }\end{array}$ \\
\hline $\begin{array}{l}\text { Nicolaou } \\
(2004)\end{array}$ & $\begin{array}{l}\text { Séries de } \\
\text { Tempo } \\
\text { (Regressão) }\end{array}$ & Contábil & $\begin{array}{l}\text { Investimentos em } \\
\text { ERP - Enterprise } \\
\text { Resource Planning } \\
\text { systems. }\end{array}$ & $\begin{array}{l}\text { Índices de } \\
\text { rentabilidade, } \\
\text { Custos }\end{array}$ & $\begin{array}{l}\text { Características de implementação, } \\
\text { escolha do fornecedor, } \\
\text { módulos implementados e } \\
\text { período de tempo de } \\
\text { implementação de ERP e efeitos } \\
\text { no desempenho. }\end{array}$ \\
\hline $\begin{array}{l}\text { Hu e Plant } \\
(2001)\end{array}$ & $\begin{array}{l}\text { Análise de } \\
\text { séries de } \\
\text { tempo } \\
\text { Modelo de } \\
\text { causalidade } \\
\text { de Granger }\end{array}$ & $\begin{array}{l}\text { Contábil e } \\
\text { de Mercado }\end{array}$ & $\begin{array}{l}\text { Investimentos em TI, } \\
\text { Custos Operacionais, } \\
\text { Crescimento de } \\
\text { Vendas e } \\
\text { Produtividade. }\end{array}$ & $\begin{array}{l}\text { Rentabilidade - } \\
\text { sobre Ativos } \\
\text { (ROA) e sobre } \\
\text { PL ( ROE). }\end{array}$ & $\begin{array}{l}\text { Mensuração do valor da TI. } \\
\text { Dificuldade em encontrar } \\
\text { causalidade instantânea entre } \\
\text { investimento em TI } \\
\text { desempenho da empresa. } \\
\text { Modelo de pesquisa para } \\
\text { investigar se os investimentos em } \\
\text { TI nos anos anteriores } \\
\text { contribuíram para as mudanças } \\
\text { subsequentes em medidas de } \\
\text { desempenho (custo operacional, } \\
\text { produtividade, crescimento de } \\
\text { vendas e rentabilidade). }\end{array}$ \\
\hline $\begin{array}{l}\text { Menon et al. } \\
(2000)\end{array}$ & $\begin{array}{l}\text { Função de } \\
\text { Produção } \\
\text { Cobb- } \\
\text { Douglas }\end{array}$ & Contábil & $\begin{array}{l}\text { Dispêndio com Ativo } \\
\text { Fixo (TI para área } \\
\text { médica), } \\
\text { Funcionários de TI e } \\
\text { trabalho não-TI. }\end{array}$ & $\begin{array}{l}\text { Receita } \\
\text { Hospitalares (de } \\
\text { Encargos dos } \\
\text { pacientes). }\end{array}$ & $\begin{array}{l}\text { Gastos de TI e Ativos de TI (área } \\
\text { médica) têm uma influência } \\
\text { positiva sobre a produção de } \\
\text { serviços em hospitais. }\end{array}$ \\
\hline Devaraj e & Regressão & Contábil & TI (trabalho, apoio e & Receita do & Investimento em TI leva a uma \\
\hline
\end{tabular}

$2 \quad$ Engle e Granger (1987): Se duas séries não estacionárias formarem um vetor de coeficientes que gerem resíduos estacionários, diz-se que estas séries cointegram. As séries não estacionárias; são então, ditas integradas de ordem $1(I(1))$, enquanto que as séries estacionárias são ditas integradas de ordem zero $(I(0))$.

REAd | Porto Alegre - Edição 83 - Nº 1 - janeiro/abril 2016 - p. 134-165 
Luci Longo \& Fernando De Souza Meirelles

\begin{tabular}{|l|l|l|l|l|l|}
\hline Kohli (2000) & & $\begin{array}{l}\text { Investimentos de } \\
\text { capital), BPR }\end{array}$ & $\begin{array}{l}\text { hospital, } \\
\text { mortalidade de } \\
\text { paciente, e nível } \\
\text { de satisfação. }\end{array}$ & $\begin{array}{l}\text { maior rentabilidade } \\
\text { e resultados de qualidade entre os } \\
\text { hospitais. }\end{array}$ \\
\hline $\begin{array}{l}\text { Hitt e } \\
\text { Brynjolfsson } \\
(1996)\end{array}$ & $\begin{array}{l}\text { Mínimos } \\
\text { Quadrados } \\
\text { Ordinários } \\
\text { (MQO) } \\
\text { Função de } \\
\text { Produção } \\
\text { Cobb- } \\
\text { Douglas }\end{array}$ & Contábil & $\begin{array}{l}\text { Gastos em TI, } \\
\text { Ativos de Não-TI, } \\
\text { intenside de capital, } \\
\text { relação dívida / } \\
\text { capital próprio, quota } \\
\text { de mercado, mão de } \\
\text { obra, } \\
\text { crescimento de } \\
\text { vendas }\end{array}$ & $\begin{array}{l}\text { Retorno sobre o } \\
\text { Ativo (ROA), } \\
\text { Retorno sobre o }\end{array}$ & $\begin{array}{l}\text { Investimento em TI proporciona } \\
\text { aumento da produtividade e } \\
\text { valor para o consumidor, mas não } \\
\text { na rentabilidade da firma. }\end{array}$ \\
\hline
\end{tabular}

Fonte: Elaborado pelos autores

Sobre obtenção dos dados e perspectivas, Masli, Richardson, Sanches e Smith (2011) lembram que a qualidade de dados permanece um dos problemas para a pesquisa que analisa os investimentos em TI e as contribuições para o valor do negócio.

Lim, Dehning, Richardson e Smith (2011), afirmam que os estudos de gastos de TI costumam ter tamanhos de amostras maiores, o que também melhora a precisão. Porém, a disponibilidade de dados de gastos com TI é limitada, uma vez que as empresas não informam em separado, despesas ou investimentos em TI nas demonstrações financeiras, sendo essa uma das implicações para pesquisadores e profissionais de AIS.

\subsection{Efeito Tardio da TI - Lag Effect}

O efeito defasado (tardio), ou lag effect tem sido identificado por muitos estudos realizados na área de SI/TI, como assimetria entre investimento e retorno. O efeito tardio de determinados investimentos de TI no desempenho e em outros benefícios que lhe são conferidos ocorrem, em geral, devido à complexidade e à extensão da iniciativa de TI, tornando a avaliação desta com o desempenho da organização bem mais complicada e exigindo análises que considerem um espaço de tempo mais longo (HU; PLANT, 2001; DEVARAJ; KOHLI, 2003; LEE; KIM, 2006; SEDDON; CALVERT; YANG, 2010; MITHAS; TAFTI; BARDHAN; GOH, 2012).

$\mathrm{O}$ efeito defasado dos investimentos em TI pode ser maior do que o efeito (impacto) imediato. Por isso, é necessário considerar um intervalo de tempo entre o investimento em TI e o desempenho da empresa (HU; PLANT, 2001; LEE; KIM, 2006; LUNARDI; BECKER; MAÇADA, 2012).

REAd | Porto Alegre - Edição 83 - Nº 1 - janeiro/abril 2016 - p. 134-165 


\section{IMPACTO DOS INVESTIMENTOS EM TECNOLOGIA DE INFORMAÇÃO NO DESEMPENHO FINANCEIRO DAS INDÚSTRIAS BRASILEIRAS}

\subsection{Embasamento para o Modelo de Pesquisa}

Visando compreender e dar destaque ao modelo de pesquisa, detalhado no Método da Pesquisa, a seguir apresenta-se alguns estudos antecessores que evidenciam a efetividade de conversão dos gastos e investimentos em TI, que se traduz em melhoria do desempenho organizacional, conforme Figura 1.

Primeiramente, apresenta-se o modelo de McKeen, Heather e Parent (1999), relacionando de forma direta o investimento com o desempenho organizacional.

No trabalho de Weill (1989) surgiu o conceito de conversão eficaz da TI ou efetividade de conversão. O mesmo salienta a necessidade de separar os diferentes tipos de investimento e combiná-los com medidas de desempenho organizacionais adequados, além da necessidade de considerar fatores como compromisso de gestão e experiência anterior com TI, podendo interferir na eficácia com que a empresa converte investimento em saídas úteis. E, Weill e Broadbent (1998) dão destaque para a classificação dos objetivos da TI, necessidades informacional, estratégica, transacional e de infraestrutura. Lucas (1999) reforça os tipos de investimentos e o uso apropriado da TI como alavancadores de desempenho; no seu modelo, admite que outras variáveis, além TI, podem direcionar o desempenho organizacional.

Dehning e Richardson (2002) apresentam entre 1997 a $2001^{3}$ um quadro de referência das pesquisas sobre avaliação dos impactos dos investimentos em TI no desempenho da firma. Os autores se detêm em medidas de desempenho organizacionais mais relevantes para os pesquisadores de AIS. Segundo os autores os investimentos em TI podem gerar impacto direto ou indireto para o processo de negócio, sendo que ambos (direto e indireto) determinam o desempenho global da organização e adotam medidas contábeis e de mercado.

Todos os modelos de pesquisa apresentados aproximam-se em termos de evidenciação, reconhecendo que os investimentos em TI podem gerar impactos na performance organizacional (desempenho).

\footnotetext{
3 International Conference on Information Systems e American Accounting Association Annual Meeting.
}

REAd | Porto Alegre - Edição 83 - N 1 - janeiro/abril 2016 - p. 134-165 
Luci Longo \& Fernando De Souza Meirelles

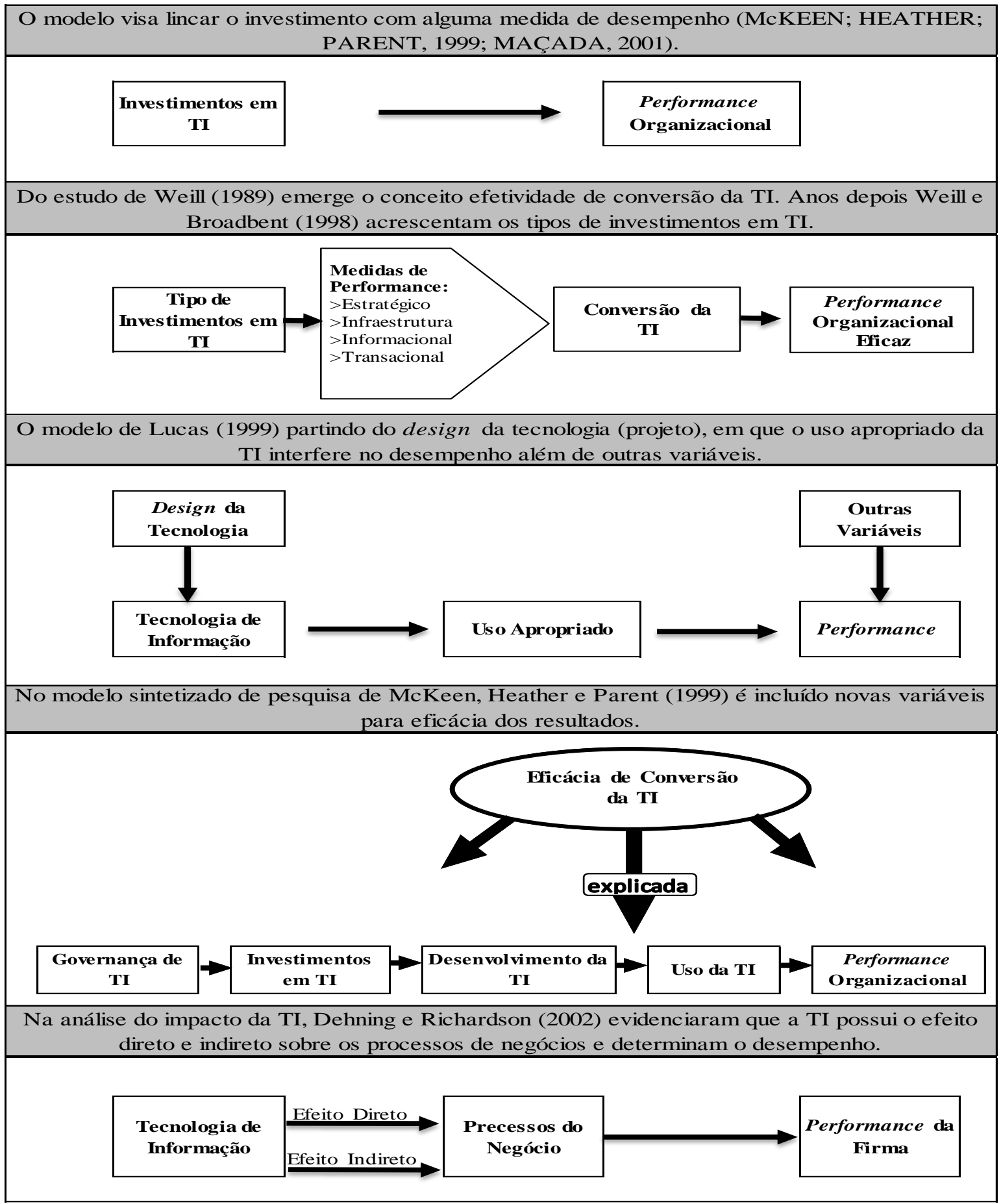

Figura 1 - Modelos para evidenciar a conversão dos Investimentos em TI na Performance

Fonte: Elaborado pelos autores

\section{MÉTODO DE PESQUISA}

REAd | Porto Alegre - Edição 83 - № 1 - janeiro/abril 2016 - p. 134-165 


\section{IMPACTO DOS INVESTIMENTOS EM TECNOLOGIA DE INFORMAÇÃO NO DESEMPENHO FINANCEIRO DAS INDÚSTRIAS BRASILEIRAS}

\subsection{População e Coleta de Dados}

A população da pesquisa foi composta pelas companhias brasileiras, de capital aberto, do ramo industrial, com ações ativas na BOVESPA, totalizando 119 companhias, para as quais foram coletadas as informações contábil-financeiras do período de 2001 a 2011, junto ao banco de dados da Economática. A coleta foi completada por meio de uma survey, para obtenção dos dados específicos das indústrias no que se refere à tecnologia de informação. Obteve-se ao final de coleta dos dados primários uma amostra com $53 \%$ da população estudada.

\subsection{Modelo e Construtos}

A evolução das pesquisas anteriores serviu de base para o modelo híbrido adotado, restringindo-se em esclarecer a efetividade de conversão dos gastos e investimentos em TI no desempenho financeiro da firma (WEILL, 1989, 1992; WEILL; BROADBENT, 1998; McKEEN; HEATHER; PARENT, 1999; LUCAS, 1999; MAÇADA, 2001; DEHNING; RICHARDSON, 2002).

A seguir apresenta-se a descrição das hipóteses. Na Figura 2, contemplando o objetivo da pesquisa, os investimentos em TI (prévios e presentes), bem como a variação destes gastos durante todo o período de análise são evidenciados no modelo.

Hipótese 1a: A variação dos gastos e investimentos em tecnologia de informação ( $\triangle \% I G T I)$ tem uma relação positiva com o aumento da receita da firma no período.

Hipótese 2a: A variação dos gastos e investimentos em TI tem uma associação negativa com os custos (despesas) operacionais da empresa.

Hipótese 3a: Os Gastos e investimentos em TI têm uma relação positiva com o aumento da rentabilidade sobre ativos ( $R O A)$.

Hipótese 1b: Os gastos e investimentos em TI realizados previamente impactam no resultado financeiro operacional (ROP) no período atual.

Hipótese 2b: Gastos e investimentos em TI do período atual (ano corrente) ou do período anterior impactam no ROP atual.

Hipótese 3b: A melhoria prévia da margem de custos da indústria possui relação positiva com a melhoria do resultado operacional atual.

REAd | Porto Alegre - Edição 83 - N 1 - janeiro/abril 2016 - p. 134-165 
Luci Longo \& Fernando De Souza Meirelles

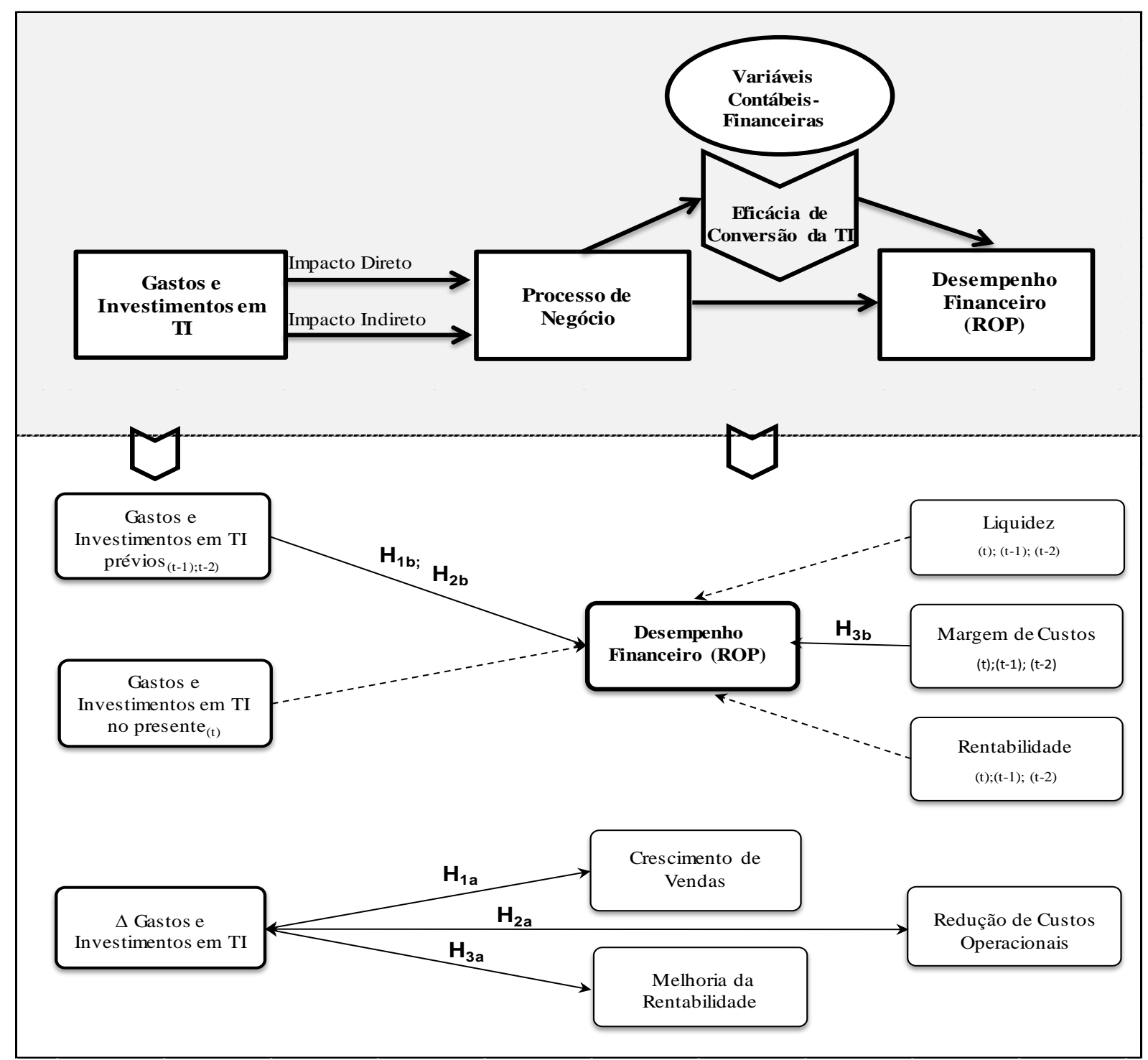

Figura 2 - Modelo de pesquisa

Fonte: Elaborado pelos autores

\subsection{Variáveis e Operacionalização}

Adotou-se a análise de dados em painel, para identificar como os gastos e investimentos em TI e outras variáveis independentes selecionadas impactam no Resultado Operacional (ROP). O índice EBIT, do acrônimo Earning Before Interest and Taxes, no Brasil, Lucro antes dos Juros, Imposto de Renda e Constribuição Social, foi adotado para representar a variável dependente ROP, devido ao reconhecimento da literatura e respaldo da legislação quanto a sua importância e adequação para representar o lucro operacional. O EBIT

REAd | Porto Alegre - Edição 83 - Nº 1 - janeiro/abril 2016 - p. 134-165 


\section{IMPACTO DOS INVESTIMENTOS EM TECNOLOGIA DE INFORMAÇÃO NO DESEMPENHO FINANCEIRO DAS INDÚSTRIAS BRASILEIRAS}

corresponde a medida de lucro mais ligada ao resultado de natureza operacional auferido pela organização, que não inclui resultado financeiro, dividendos ou juros sobre o capital próprio, resultado de equivalência patrimonial e outros resultados não operacionais (MARQUES; CARNEIRO JR; KUHL, 2008; MATARAZZO, 2010).

Além da variável dependente ROP, a matriz de dados foi composta por 11(onze) variáveis independentes, conforme apresentadas na Tabela 2.

Tabela 2 - Detalhamento das variáveis

\begin{tabular}{|c|c|c|c|}
\hline Variável & Pesquisas & Equação & Descrição da Variável \\
\hline $\begin{array}{l}\text { Resultado } \\
\text { Operacional }\end{array}$ & $\begin{array}{l}\text { Mithas et al. (2012) } \\
\text { Kohli et al. (2012) } \\
\text { Lunardi et al.(2012) }\end{array}$ & $R O P_{t}=E B I T$ & Lucro antes dos Juros e Imposto de Renda. \\
\hline Gastos em TI & $\begin{array}{l}\text { Meirelles, }(1985,2015) \\
\text { Hu e Plant }(2001) \\
\text { Aral e Weill }(2007) \\
\text { Henderson et al.(2010) } \\
\text { Kohli et al. (2012) }\end{array}$ & $I G T I_{t}=\frac{G}{R O L}$ & $\begin{array}{l}\text { Investimentos, Custos e Despesas destinadas } \\
\text { à Tecnologia de Informação (Valor Anual). }\end{array}$ \\
\hline $\begin{array}{l}\text { Custo } \\
\text { Operacional }\end{array}$ & $\begin{array}{l}\text { Hu e Plant (2001) } \\
\text { Lunardi et al. (2012) }\end{array}$ & $\begin{array}{l}\text { CustOp }_{t}=\text { Dadm }+ \\
\text { Dvendas }\end{array}$ & $\begin{array}{l}\text { Valor anual das Despesas Administrativas e } \\
\text { de Despesas de Vendas, excluídos despesas } \\
\text { financeiras. }\end{array}$ \\
\hline $\begin{array}{l}\text { Retorno sobre } \\
\text { Ativos (ROA) }\end{array}$ & $\begin{array}{l}\text { Dunn et al. (2009) } \\
\text { Kobelsky et al. (2008) } \\
\text { Parente e Van Horn } \\
\text { (2007); } \\
\text { Aral e Weill (2007) } \\
\text { Hu e Plant (2001) } \\
\text { Hitt e Brynjolfsson (1996) }\end{array}$ & $R O A_{t}=\frac{L O p}{A T}$ & $\begin{array}{l}\text { Indicador de Rentabilidade sobre Ativo } \\
\text { Total (ROA-Return on Assets). }\end{array}$ \\
\hline Giro do Ativo & $\begin{array}{l}\text { Dehning et al. (2007) } \\
\text { Lunardi et al. (2012) }\end{array}$ & Giro-Ativo $_{t}=\frac{R O L}{A T}$ & $\begin{array}{l}\text { Traduz o giro, ou seja, a Receita expressa o } \\
\text { volume de negócios pelos investimentos totais } \\
\text { (AT). }\end{array}$ \\
\hline $\begin{array}{l}\text { Retorno sobre o } \\
\text { PL (ROE) }\end{array}$ & $\begin{array}{l}\text { Hu e Plant (2001) } \\
\text { Hitt e Brynjolfsson (1996) }\end{array}$ & $\operatorname{ROE}_{t}=\frac{L O p}{P L}$ & $\begin{array}{l}\text { Representa a rentabilidade Operacional do } \\
\text { PL, obtido da divisão do (ROP) pelo } \\
\text { Patrimônio Líquido (PL). }\end{array}$ \\
\hline $\begin{array}{l}\text { Custo do } \\
\text { Produto } \\
\text { Vendido }\end{array}$ & Aral e Weill (2007) & $\operatorname{CusProd}_{t}=C P V$ & $\begin{array}{l}\text { Valor do Custo do Produto Vendido (total } \\
\text { do custo de produção, mais adicionais da } \\
\text { venda) }\end{array}$ \\
\hline $\begin{array}{l}\text { Margem de } \\
\text { Contribuição } \\
\text { Bruta }\end{array}$ & Shin (2006) & $M C_{t}=R O-C V a r$ & $\begin{array}{l}\text { Evidencia o resultado parcial, obtido do } \\
\text { cálculo da Receita Líquida, deduzidos os } \\
\text { Custos Variáveis de Produção. }\end{array}$ \\
\hline $\begin{array}{l}\text { Margem de } \\
\text { Contribuição } \\
\text { Operacional }\end{array}$ & Shin (2006) & $\begin{array}{l}\text { MCOper }_{t}=M C- \\
\text { VarVendas }\end{array}$ & $\begin{array}{l}\text { Evidencia o resultado parcial, a partir do } \\
\text { Resultado da MC deduzidos os Custos } \\
\text { Variáveis de Vendas (incluíndo impostos de } \\
\text { Vendas). }\end{array}$ \\
\hline $\begin{array}{l}\text { Crescimento de } \\
\text { Vendas }\end{array}$ & $\begin{array}{l}\text { Hu e Plant (2001) } \\
\text { Hitt e Brynjolfsson (1996) } \\
\text { Lunardi et al. (2012) }\end{array}$ & $\Delta \operatorname{Vendas}_{i}=\frac{V_{t}-V_{t-n}}{V_{t-n}}$ & $\begin{array}{l}\text { Representa a Variação das Vendas } \\
\text { (Crescimento ou Redução no período }\left(\mathrm{V}_{\text {tinicial }}\right. \\
\left.-\mathrm{t}_{\text {final }}\right) \text {. }\end{array}$ \\
\hline
\end{tabular}

REAd | Porto Alegre - Edição 83 - № 1 - janeiro/abril 2016 - p. 134-165 
Luci Longo \& Fernando De Souza Meirelles

\begin{tabular}{|c|c|c|c|}
\hline Capital de Giro & $\begin{array}{l}\text { Dunn et al. (2009) } \\
\text { Beasley et al. (2009) }\end{array}$ & CapGiro $=A C O p$ & $\begin{array}{l}\text { Indica os recursos no } \\
\text { relacionados às operações } \\
\text { créditos e estoques), obtido no } \\
\text { (disponível, } \\
\text { Circulante. }\end{array}$ \\
\hline $\begin{array}{l}\text { Liquidez } \\
\text { Corrente }\end{array}$ & & $\operatorname{Liq}_{t}=\frac{A C}{P C}$ & $\begin{array}{l}\text { Índice de Liquidez de curto prazo evidencia } \\
\text { a capacidade de saldar as obrigações dentro } \\
\text { do ano. }\end{array}$ \\
\hline
\end{tabular}

Fonte: Elaborado na pesquisa

\subsection{Características do Modelo Adotado}

Os dados em painel permitem a avaliação da relação dinâmica entre as variáveis, possibilitando a incorporação de uma possível existência de correlação entre os valores presentes e passados da variável dependente (ROP) e os valores contemporâneos e passados das demais variáveis independentes ou explicativas (IGTI, ROA, LiqC, Giro-Ativo, ROE, Cap-Giro e MCOper). Além disso, é importante considerar a característica específica de cada empresa analisada, apesar de não ser possível observá-la (por exemplo, política, missão e estratégia da empresa).

Para o estudo, o efeito específico da empresa é considerado fixo e invariante no tempo. Admite-se ainda, neste modelo, uma possível correlação entre as variáveis explicativas e o efeito fixo específico de cada empresa (endogeneidade).

Foram utilizadas as informações referentes ao período de 2001 a 2011, compreendendo 11(onze) instantes de tempo, sendo que para não ocorrer uma redução excessiva no tamanho de amostra para a estimação do modelo, foram consideradas defasagens de até dois instantes de tempo. A regressão estimada neste trabalho apresenta a seguinte parametrização:

$$
y_{i t}=\alpha_{1} y_{i, t-1}+\alpha_{2} y_{i, t-2}+\mathbf{x}_{\mathbf{i t}} \boldsymbol{\beta}_{1}+\mathbf{x}_{\mathbf{i}, \mathbf{t}-1} \boldsymbol{\beta}_{2}+\varepsilon_{i t}
$$

Sendo:

$\mathrm{i}=1 \mathrm{a} \mathrm{N} ; \quad$ para $\mathrm{t}=2003, \ldots, 2011$

$\varepsilon_{i t}=\mu_{i}+v_{i t}$

$E\left[\mu_{i}\right]=E\left[v_{i t}\right]=E\left[\mu_{i} v_{i t}\right]=0$

Onde: $\boldsymbol{x}_{i t}, \boldsymbol{x}_{i, t-1}, \boldsymbol{x}_{i, t-2}$ são vetores de variáveis explicativas contemporâneas e defasadas de um e dois instantes de tempo, respectivamente, de dimensão $\mathbf{1}$ x $\mathbf{p}$ e $\boldsymbol{\beta}$ o vetor de REAd | Porto Alegre - Edição 83 - Nº 1 - janeiro/abril 2016 - p. 134-165 


\section{IMPACTO DOS INVESTIMENTOS EM TECNOLOGIA DE INFORMAÇÃO NO DESEMPENHO FINANCEIRO DAS INDÚSTRIAS BRASILEIRAS}

coeficientes, $\mathbf{p} \times \mathbf{1}$, associado a esses regressores. O componente de erro do modelo, $\boldsymbol{\varepsilon}_{\mathbf{i t}}$, é composto por dois elementos ortogonais: um componente aleatório idiossincrático $\boldsymbol{v}_{i t}$ e efeitos individuais fixos constantes no tempo, $\boldsymbol{\mu}_{\mathbf{i}}$.

Por construção, a variável dependente defasada é correlacionada com o efeito fixo, que é parte do componente de erro do modelo. Desta forma, caso o modelo (Equação 1) seja estimado pelo método de mínimos quadrados ordinários, os coeficientes estimados serão viesados.

A solução adotada para o problema consiste em transformar os dados de modo a eliminar o efeito fixo:

$y_{i t}-y_{i, t-1}=\alpha_{1}\left(y_{i, t-1}-y_{i, t-2}\right)+\alpha_{2}\left(y_{i, t-2}-y_{i, t-3}\right)+\left(\mathbf{x}_{\mathbf{i t}}-\mathbf{x}_{\mathbf{i}, \mathbf{t}-1}\right) \boldsymbol{\beta}_{1}+\left(\mathbf{x}_{\mathbf{i}, \mathbf{t}-1}-\mathbf{x}_{\mathbf{i}, \mathbf{t}-2}\right) \boldsymbol{\beta}_{2}+\left(\varepsilon_{i t}-\varepsilon_{i, t-1}\right)$

Simplificando, a representação da variação ficou assim:

$$
\Delta y_{i t}=\alpha_{1} \Delta y_{i, t-1}+\alpha_{2} \Delta y_{i, t-2}+\Delta \mathbf{x}_{\mathbf{i t}} \boldsymbol{\beta}_{1}+\Delta \mathbf{x}_{\mathbf{i}, \mathbf{t}-1} \boldsymbol{\beta}_{2}+\Delta v_{i t}
$$

Pode-se observar que, após a transformação, a variável dependente defasada apresenta ainda um componente endógeno, uma vez que o termo $\mathbf{y}_{\mathbf{i}, \mathrm{t}-\mathbf{1}}$ é, por definição, correlacionado $\operatorname{com} \mathbf{v}_{\mathbf{i}, \mathbf{t}-1}$.

Arellano e Bond (1991) propuseram a utilização dos valores defasados de $\boldsymbol{y}_{i, t-1}$ como instrumentos ${ }^{4}$ para $\Delta \mathbf{y}_{\mathbf{i}, \mathbf{t}-1}$ sob a hipótese de que não exista correlação serial em $\mathbf{v}_{\mathbf{i t}}$. Dessa forma, $\mathbf{y}_{\mathbf{i}, \mathbf{t - 2}}$ é matematicamente relacionado com $\Delta \mathbf{y}_{\mathbf{i}, \mathbf{t}-1}$ e, ao mesmo tempo, não correlacionado com o erro em primeira diferença $\Delta \mathbf{v}_{\mathbf{i t}}=\mathbf{v}_{\mathbf{i t}}-\mathbf{v}_{\mathbf{i}, \mathbf{t}-\mathbf{1}}$.

À medida que o painel avança no tempo, sucessivas defasagens podem ser incorporadas, gerando assim um subconjunto de instrumentos válidos para cada período disponível. O mesmo processo pode ser aplicado no caso das demais variáveis explicativas, consideradas como potencialmente endógenas. Arellano e Bond (1991) desenvolveram um procedimento de estimação linear via método dos momentos generalizado (GMM), e não correlacionada com o componente de erro aleatório do modelo de regressão.

REAd | Porto Alegre - Edição 83 - N 1 - janeiro/abril 2016 - p. 134-165 
Luci Longo \& Fernando De Souza Meirelles

Generalized Method of Moments, que utiliza os sucessivos valores defasados das variáveis endógenas como instrumentos para a primeira diferença dessas variáveis.

As estimativas geradas pelo estimador GMM dependem da validade dos instrumentos empregados na identificação das variáveis endógenas que foi testada empregando-se o teste de Sargan.

O teste de Sargan é um teste estatístico utilizado para verificar se há restrições de identificação de um modelo estatístico. Os resíduos deverão ser correlacionados com o conjunto de variáveis exógenas se os instrumentos forem verdadeiramente exógenos (WOOLDRIDGE, 2010, p.135).

Além disso, o modelo pressupõe a ausência de correlação serial no erro idiossincrático $v_{i t}$, condição necessária para a consistência do estimador $\mathrm{GMM}^{5}$. Para testar esse pressuposto, foi utilizado o teste desenvolvido por Arellano e Bond (1991), aplicado aos resíduos em diferenças. Sob a hipótese nula de ausência de correlação serial de segunda ordem nos distúrbios em primeira diferença, $\Delta \mathbf{v}_{\mathbf{i t}}$, não existe correlação de primeira ordem nos distúrbios em nível.

\section{APRESENTAÇÃO DOS RESULTADOS}

\subsection{Análise dos impactos dos GITI no Desempenho Financeiro (ROP)}

Conforme explicado na metodologia, devido à presença de heterogeneidade não observável na forma de efeito fixo, o modelo pelo método de mínimos quadrados ordinários (MQO) não se mostra adequado. Para tratar o efeito fixo, foi utilizado o modelo ajustado de Arellano e Bond (1991).

As análises foram efetuadas com o software estatístico Data Analysis and Statistical Software STATA ${ }^{\circledR}$ versão 12.0. Inicialmente, todas as variáveis explicativas foram incluídas no modelo e aquelas não significantes foram eliminadas uma a uma por ordem de significância. Para o ajuste deste modelo, foi considerado o nível de significância de $5 \%$.

5 Considerando que os distúrbios são não correlacionados entre indivíduos e observado o teorema do limite central, a estatística de teste segue, assintoticamente, a distribuição normal padrão.

REAd | Porto Alegre - Edição 83 - N 1 - janeiro/abril 2016 - p. 134-165 


\section{IMPACTO DOS INVESTIMENTOS EM TECNOLOGIA DE INFORMAÇÃO NO DESEMPENHO FINANCEIRO DAS INDÚSTRIAS BRASILEIRAS}

Algumas variáveis foram mantidas no modelo como variável de controle, apesar de não serem significantes ${ }^{6}$ (ROE, crescimento de vendas e defasagens de algumas variáveis que tiveram algum período significante).

No Apêndice (A) encontram-se as medidas-resumo das variáveis analisadas. Na Tabela 3 deu-se destaque para as estimativas dos coeficientes do modelo inicial e algumas variáveis não se mostraram significativas.

$\underline{\text { Tabela } 3 \text { - Estimativa dos coeficientes do modelo de regressão inicial }}$

\begin{tabular}{|c|c|c|c|c|c|}
\hline $\mathbf{R O P}_{(\mathrm{t})}$ & Coeficiente & $\begin{array}{c}\text { Erro } \\
\text { Padrão } \\
\text { Robusto[1] }\end{array}$ & $\mathbf{Z}$ & $\mathbf{p}$ & $\begin{array}{l}\text { Intervalo de } \\
\text { Confiança de } \\
95 \% \text { para o } \\
\text { coeficiente }\end{array}$ \\
\hline \multicolumn{6}{|l|}{ ROP } \\
\hline $\mathrm{ROP}_{(\mathrm{t}-1)}$ & 0,02 & 0,04 & 0,59 & 0,556 & {$[-0,05 ; 0,09]$} \\
\hline $\mathrm{ROP}_{(\mathrm{t}-2)}$ & 0,07 & 0,04 & 1,84 & 0,065 & {$[0,00 ; 0,14]$} \\
\hline \multicolumn{6}{|l|}{ ROA } \\
\hline $\mathrm{ROA}_{(\mathrm{t})}$ & 0,49 & 0,16 & 3,08 & 0,002 & {$[0,18 ; 0,81]$} \\
\hline $\mathrm{ROA}_{(t-1)}$ & $-0,04$ & 0,07 & $-0,61$ & 0,539 & {$[-0,17 ; 0,09]$} \\
\hline $\mathrm{ROA}_{(t-2)}$ & $-0,08$ & 0,04 & $-1,91$ & 0,056 & {$[-0,17 ; 0,00]$} \\
\hline \multicolumn{6}{|l|}{ LiqC } \\
\hline $\operatorname{LiqC}_{(t)}$ & 0,028 & 0,015 & 1,83 & 0,068 & {$[-0,002 ; 0,058]$} \\
\hline $\operatorname{LiqC}_{(t-1)}$ & $-0,02$ & 0,02 & $-1,3$ & 0,193 & {$[-0,06 ; 0,01]$} \\
\hline $\operatorname{LiqC}_{(t-2)}$ & 0,01 & 0,01 & 1,13 & 0,26 & {$[-0,01 ; 0,03]$} \\
\hline \multicolumn{6}{|l|}{ Giro-Ativo } \\
\hline Giro-Ativo $_{(\mathbf{t})}$ & $-0,05$ & 0,04 & $-1,18$ & 0,237 & {$[-0,13 ; 0,03]$} \\
\hline Giro-Ativo $_{(t-1)}$ & 0,01 & 0,03 & 0,3 & 0,768 & {$[-0,05 ; 0,06]$} \\
\hline Giro-Ativo $_{(t-2)}$ & $-0,04$ & 0,03 & $-1,1$ & 0,27 & {$[-0,10 ; 0,03]$} \\
\hline \multicolumn{6}{|l|}{ ROE } \\
\hline $\mathrm{ROE}_{(t)}$ & 0,003 & 0,006 & 0,52 & 0,601 & {$[-0,009 ; 0,015]$} \\
\hline $\mathrm{ROE}_{(t-1)}$ & 0 & 0 & 0,76 & 0,445 & {$[-0,01 ; 0,01]$} \\
\hline $\mathrm{ROE}_{(t-2)}$ & 0 & 0,01 & 0,58 & 0,563 & {$[-0,01 ; 0,01]$} \\
\hline \multicolumn{6}{|l|}{ Cap-Giro } \\
\hline Cap-Giro $_{(t)}$ & $-0,11$ & 0,06 & $-1,93$ & 0,054 & {$[-0,21 ; 0,00]$} \\
\hline Cap-Giro & 0,09 & 0,04 & 2,24 & 0,025 & {$[0,01 ; 0,17]$} \\
\hline Cap-Giro & 0,05 & 0,03 & 1,55 & 0,121 & {$[-0,01 ; 0,12]$} \\
\hline \multicolumn{6}{|l|}{ IGTI } \\
\hline $\operatorname{IGTI}_{(t)}$ & 1,79 & 3,22 & 0,55 & 0,579 & {$[-4,52 ; 8,10]$} \\
\hline $\operatorname{IGTI}_{(t-1)}$ & $-1,09$ & 3,04 & $-0,36$ & 0,72 & {$[-7,05 ; 4,87]$} \\
\hline
\end{tabular}

6 Algumas foram mantidas no modelo, apesar de não significantes, como controle. A exclusão dessas variáveis acarretariam em alterações (mais de 20\%) nas estimativas ou perdas da significância de outras variáveis presentes no modelo.

REAd | Porto Alegre - Edição 83 - Nº 1 - janeiro/abril 2016 - p. 134-165 
Luci Longo \& Fernando De Souza Meirelles

\begin{tabular}{|c|c|c|c|c|c|}
\hline IGTI $_{(t-2)}$ & 5,82 & 3,48 & 1,67 & 0,094 & {$[-1,00 ; 12,63]$} \\
\hline \multicolumn{6}{|l|}{ MCOper } \\
\hline MCOper $_{(t)}$ & 0,53 & 0,2 & 2,58 & 0,01 & {$[0,13 ; 0,93]$} \\
\hline MCOper $_{(t-1)}$ & 0,25 & 0,17 & 1,43 & 0,151 & {$[-0,09 ; 0,59]$} \\
\hline MCOper $_{(t-2)}$ & $-0,04$ & 0,08 & $-0,51$ & 0,609 & {$[-0,19 ; 0,11]$} \\
\hline \multicolumn{6}{|l|}{ Crescimento de Vendas (\%) } \\
\hline Crescimento de Vendas $_{(t)}$ & $-0,01$ & 0,04 & $-0,32$ & 0,75 & {$[-0,09 ; 0,07]$} \\
\hline 1) Crescimento de Vendas $_{(\mathrm{t}-}$ & 0 & 0,03 & 0,08 & 0,937 & {$[-0,05 ; 0,06]$} \\
\hline${ }_{2)}$ Crescimento de Vendas $(t-$ & 0,03 & 0,01 & 1,96 & 0,05 & {$[0,00 ; 0,06]$} \\
\hline Constante & $-0,06$ & 0,14 & $-0,44$ & 0,661 & {$[-0,34 ; 0,22]$} \\
\hline
\end{tabular}

Coleta finalizada em Outubro de 2012

Fonte: Dados da pesquisa

Notas:

[1] Erro Padrão corrigido para potencial existência de heterocedasticidade e auto correlação serial nos componentes de erro nas informações de uma mesma empresa.

Teste de auto correlação nos resíduos em primeira diferença de ordem 1: $\mathrm{p}=0,107$; ordem 2: $\mathrm{p}=0,500$ e ordem 3: $\mathrm{p}=0,585$.

Teste de Sargan (teste da validade de sobre identificação das restrições): $p=0.550$.

Número de observações - 434 relativas a 63 empresas

\subsection{Resultados Finais e Análise}

Por fim a Tabela 4 evidencia as estimativas dos coeficientes do modelo de regressão final (reduzido), com as variáveis selecionadas, assim como as variáveis de controle (ROE e Crescimento de Vendas).

Tabela 4 - Estimativa dos coeficientes do modelo final

\begin{tabular}{|c|c|c|c|c|c|}
\hline $\mathbf{R O P}_{(\mathbf{t})}$ & Coeficiente & $\begin{array}{l}\text { Erro } \\
\text { Padrão } \\
\text { robusto }\end{array}$ & $\mathbf{Z}$ & $\mathbf{p}$ & $\begin{array}{c}\text { Intervalo de } \\
\text { Confiança de } 95 \% \\
\text { para o coeficiente }\end{array}$ \\
\hline \multicolumn{6}{|l|}{ ROP } \\
\hline $\mathrm{ROP}_{(\mathrm{t}-1)}$ & $-0,02$ & 0,03 & $-0,68$ & 0,499 & {$[-0,08 ; 0,04]$} \\
\hline $\mathrm{ROP}_{(\mathrm{t}-2)}$ & 0,04 & 0,02 & 2,65 & 0,008 & {$[0,01 ; 0,08]$} \\
\hline \multicolumn{6}{|l|}{ ROA } \\
\hline $\mathrm{ROA}_{(\mathrm{t})}$ & 0,49 & 0,16 & 2,97 & 0,003 & {$[0,17 ; 0,81]$} \\
\hline $\mathrm{ROA}_{(\mathrm{t}-2)}$ & $-0,08$ & 0,03 & $-2,7$ & 0,007 & {$[-0,13 ;-0,02]$} \\
\hline \multicolumn{6}{|l|}{ LiqC } \\
\hline $\operatorname{LiqC}_{(\mathrm{t})}$ & 0,024 & 0,008 & 2,82 & 0,005 & {$[0,007 ; 0,04]$} \\
\hline \multicolumn{6}{|l|}{ ROE } \\
\hline $\mathrm{ROE}_{(\mathrm{t})}$ & 0,004 & 0,006 & 0,6 & 0,551 & {$[-0,008 ; 0,016]$} \\
\hline \multicolumn{6}{|l|}{ Cap-Giro } \\
\hline Cap-Giro $_{(t)}$ & $-0,1$ & 0,05 & $-1,97$ & 0,049 & {$[-0,2009 ;-0,0003]$} \\
\hline Cap-Giro ${ }_{(t-1)}$ & 0,05 & 0,07 & 0,81 & 0,419 & {$[-0,08 ; 0,18]$} \\
\hline Cap-Giro ${ }_{(t-2)}$ & 0,1 & 0,06 & 1,56 & 0,119 & {$[-0,02 ; 0,22]$} \\
\hline
\end{tabular}

REAd | Porto Alegre - Edição 83 - N 1 - janeiro/abril 2016 - p. 134-165 


\section{IMPACTO DOS INVESTIMENTOS EM TECNOLOGIA DE INFORMAÇÃO NO DESEMPENHO FINANCEIRO DAS INDÚSTRIAS BRASILEIRAS}

\begin{tabular}{|c|c|c|c|c|c|}
\hline $\operatorname{IGTI}_{(\mathrm{t}-2)}$ & 7,3 & 3,59 & 2,03 & 0,042 & {$[0,26 ; 14,33]$} \\
\hline \multicolumn{6}{|l|}{ MCOper } \\
\hline $\mathrm{MCOper}_{(t)}$ & 0,52 & 0,18 & 2,98 & 0,003 & {$[0,18 ; 0,87]$} \\
\hline $\operatorname{MCOper}_{(\mathrm{t}-1)}$ & 0,24 & 0,15 & 1,65 & 0,098 & {$[-0,04 ; 0,53]$} \\
\hline \multicolumn{6}{|l|}{ Crescimento de Vendas (\%) } \\
\hline Crescimento de Vendas & 0,03 & 0,02 & 1,74 & 0,082 & {$[-0,004 ; 0,068]$} \\
\hline 2) Crescimento de Vendas $_{(t-}$ & 0,04 & 0,02 & 1,62 & 0,104 & {$[-0,01 ; 0,09]$} \\
\hline Constant & $-0,16$ & 0,06 & $-2,63$ & 0,009 & {$[-0,29 ;-0,04]$} \\
\hline \multicolumn{6}{|c|}{$\begin{array}{l}\text { Coleta finalizada em Outubro de } 2012 \\
\text { Fonte: Dados da pesquisa } \\
\text { Notas: } \\
\text { Teste de auto correlação nos resíduos em primeira diferença de ordem 1: } \mathrm{p}=0,121 \text {; ordem 2: } \mathrm{p}=0,555 \text { e ordem } \\
\text { 3: }=0,619 \text {. }\end{array}$} \\
\hline \multicolumn{6}{|c|}{ Teste de Sargan (teste da validade de sobre identificação das restrições: $\mathrm{p}=0,430$. } \\
\hline
\end{tabular}

Conforme Tabela 4, observa-se que foram significantes no modelo o ROP de dois anos atrás $(\mathrm{p}=0,008)$, ROA no valor presente $(\mathrm{p}=0,003)$ e 2 (dois) anos atrás $(\mathrm{p}=0,007)$, LiqC no ano atual $(\mathrm{p}=0,005)$, Capital de Giro do ano presente $(\mathrm{p}=0,049)$, IGTI de dois anos atrás $(\mathrm{p}=0,042)$ e MCOper no valor presente $(\mathrm{p}=0,003)$.

A partir do modelo final, pode-se afirmar que o aumento de $1 \%$ no IGTI, ocorrido há dois anos, acarreta um aumento de 7,3\% no ROP atual, mantidas as demais variáveis do modelo controladas (quando estamos comparando duas empresas similares com LiqC, Capital de Giro, MCOP, etc. em patamares semelhantes).

Além disso, é possível observar que o aumento de $1 \%$ no ROP de dois períodos anteriores, o aumento de $1 \%$ no ROA presente, o aumento de $1 \%$ no LiqC presente e o aumento de $1 \%$ no MC Oper atual acarretam, respectivamente, um aumento de 0,04\%, 0,49\%, $0,024 \%$ e $0,52 \%$ no ROP atual. O modelo final apresentou resíduos não correlacionados até a ordem 3 e o teste de Sargan não rejeitou a validade dos instrumentos $(\mathrm{p}=0,430)$, satisfazendo às condições do modelo de Arellano e Bond.

Os resultados mostraram que houve algumas situações novas em relação ao modelo inicialmente proposto: i) o aumento da variável $\mathrm{ROA}_{\mathrm{t}-2}$ (de dois períodos passados) impacta negativamente na variável resposta ROP atual; ii) o aumento da variável Capital de Giro atual possui correlação negativa também com o ROP atual; iii) acreditava-se inicialmente que a

REAd | Porto Alegre - Edição 83 - Nº 1 - janeiro/abril 2016 - p. 134-165 


\section{Luci Longo \& Fernando De Souza Meirelles}

melhoria prévia da margem de contribuição (anos passados) impactava no ROP atual, contudo esta hipótese não foi confirmada; iv) a hipóteses de que a variável Rentabilidade do Capital Próprio (ROE) de anos anteriores está associada ao ROP atual não foi significante no modelo, também não foi confirmado que os investimentos em TI prévios provocam a melhoria da rentabilidade atual.

Sendo assim, foi possível confirmar as seguintes hipóteses, em relação à variação dos investimentos de TI no período e adotando o modelo dinâmico:

$\mathbf{H}_{1 \mathbf{a}}$ A variação dos gastos e investimentos em tecnologia de informação ( $\left.\Delta \% \mathrm{IGTI}\right)$ tem uma relação positiva com o aumento da receita da firma no período.

$\mathbf{H}_{2 \mathbf{a}}$ A variação dos gastos e investimentos em TI tem uma associação negativa com os custos (despesas) operacionais da empresa.

$\mathbf{H}_{1 \mathbf{b}}$ Os gastos e investimentos em TI realizados previamente impactam no resultado financeiro operacional (ROP) no período atual.

\section{CONCLUSÕES}

A presente pesquisa teve como objetivo geral analisar o impacto dos gastos e investimentos em TI no resultado operacional das indústrias brasileiras. Alguns destaques da pesquisa referem à quantidade de dados analisados, especialmente, considerando as pesquisas anteriores no contexto nacional, seja para o período de tempo, pois possibilitou captar a dinâmica da questão de pesquisa e compreender melhor o desempenho financeiro das indústrias, com base em indicadores, que foram fundamentais para nortear esta pesquisa: (1) Gastos e Investimentos em TI (GITI/IGTI), que representa o montante de recursos destinados a TI (OPEX/CAPEX); (2) Resultado Operacional (ROP), representando o desempenho financeiro, genuíno da atividade; (3) Crescimento de Vendas, representando a evolução das receitas operacionais das companhias estudadas; (4) Custos Operacionais (CustOp), variável composta na pesquisa pelas despesas anuais administrativas e de vendas.

Reconhecendo as experiências de pesquisas anteriores e que amostras maiores proporcionam maior confiança nos resultados. Após a coleta de dados primários, especialmente dos gastos e investimentos em TI, obteve-se dados completos e validados para mais da metade $(53 \%)$ da população da pesquisa.

REAd | Porto Alegre - Edição 83 - N 1 - janeiro/abril 2016 - p. 134-165 


\section{IMPACTO DOS INVESTIMENTOS EM TECNOLOGIA DE INFORMAÇÃO NO DESEMPENHO FINANCEIRO DAS INDÚSTRIAS BRASILEIRAS}

A pesquisa empírica permitiu concluir que as indústrias que mais investiram em TI no período, obtiveram melhor desempenho financeiro (resultado operacional). Esta conclusão foi fundamentada após as análises, por meio do modelo econométrico, adotado para análise de dados em painel, que inseriram variáveis descontadas ( $\mathrm{t}$ : dados do período atual; $\mathrm{t}-1$ : de um ano antes; t-2: dados de dois anos anteriores).

Salienta-se, ainda, que o método adotado possibilitou uma descrição da evolução das variáveis do estudo e o modelo de ajuste do efeito fixo de Arellano-Bond (1991), um procedimento de estimação linear via Método dos Momentos Generalizados, do inglês Generalized Method of Moments (GMM). O respectivo modelo adotou análise de dados em painel; dessa forma, possibilitou a identificação da relação dinâmica entre as variáveis, ou seja, a correlação entre os valores presentes e passados (anos anteriores) da variável resposta Resultado Operacional (ROP) e entre os valores presentes e passados das demais variáveis explicativas (IGTI, ROA, LiqC, Giro-Ativo, ROE, Cap-Giro e MCOper).

No modelo, foram significantes o Indicador de Gastos e Investimentos em TI IGTI $_{t-2}$, de dois anos atrás $(\mathrm{p}=0,042)$, impactando no Resultado Operacional Atual, ROP $\mathrm{t}_{\mathrm{t}}$ Os resultados mostraram significância nos gastos prévios e não no IGTI atual ou no ano imediatamente anterior, que pode ser explicada pelo efeito tardio, ou lag effect.

Levando em conta o efeito tardio dos investimentos, na pesquisa foi proposto defasagens de todas as variáveis do modelo para dois anos e o período atual (três instantes de tempo). Esta escolha foi por parcimônia, visando dar maior robustez às estimativas do modelo de Regressão, ou seja, dos valores nas colunas de coeficiente.

Analisando os resultados verifica-se que há diferenças significativas relacionadas ao uso da TI e a associação com o desempenho econômico-financeiro nas empresas pesquisadas, em especial do Resultado Operacional (ROP), o indicador do desempenho financeiro organizacional, conforme já destacado, genuinamente da atividade do setor estudado. É possível constatar a partir do modelo da pesquisa e com base nos resultados, que o aumento de $1 \%$ no Índice de Gastos e Investimentos em TI ocorridos há dois anos acarreta um aumento de 7,3\% no Resultado Operacional (atual).

Esta constatação estimula novas pesquisas, porém é oportuno registrar sua relevância tanto no aspecto acadêmico, como para o contexto empresarial, uma vez considerado as

REAd | Porto Alegre - Edição 83 - Nº 1 - janeiro/abril 2016 - p. 134-165 


\section{Luci Longo \& Fernando De Souza Meirelles}

condições do modelo de pesquisa e variáveis financeiras, as organizações, ao investir em TI, vêm obtendo, após um período de tempo, a melhoria dos seus indicadores financeiros, especialmente na esfera operacional.

No processo de investigação empírica, também foram analisadas a variação percentual ( $\Delta \%$ 2001-2011) das seguintes variáveis: i) melhoria de Vendas, ii) Variação de Custo Operacional e iii) Melhoria da Rentabilidade sobre Ativo (ROA). Houve confirmação da associação positiva dos Investimentos em TI do período com o Crescimento da Receita em 0,637 e associação negativa com Custos Operacionais em menor grau -0,332. Confirmando o crescimento de vendas e redução de custos. Não houve significância em relação à Rentabilidade sobre Ativos (ROA) para o período nas indústrias analisadas.

O desenvolvimento desta pesquisa possibilitou algumas contribuições com implicações gerenciais, assim como implicações acadêmicas. Primeiramente as contribuições acadêmicas referem-se:

a) Ao desenvolvimento de um modelo para testar hipóteses teóricas extraídas da literatura de TI;

b) Ao fato do trabalho aprofundar e ampliar as discussões existentes sobre a avaliação dos investimentos em TI e sobre a forma que as pesquisas estão aferindo o impacto destes investimentos no desempenho financeiro;

c) À adoção de uma inovação quanto ao método, na pesquisa empírica, pois buscou, por meio de análise dinâmica e tratamento do efeito fixo, eliminar a correlação espúria, evitando falhas de metodologia.

Constatou-se a limitação quanto ao acesso dos dados específicos de TI. No decorrer da pesquisa, algumas companhias selecionadas não concordaram em dar informações complementares sobre os investimentos em TI e, em outros casos, havia falhas de informações para todo o período de 2001 até 2011, compreendido na pesquisa. Mas que não prejudicou o desenvolvimento da pesquisa e suas proposições. Esta limitação foi observada em outros trabalhos empíricos.

Para pesquisas futuras, no contexto avaliação do valor da TI para o negócio e mensuração dos investimentos no desempenho, há a possibilidade de:

REAd | Porto Alegre - Edição 83 - N 1 - janeiro/abril 2016 - p. 134-165 


\section{IMPACTO DOS INVESTIMENTOS EM TECNOLOGIA DE INFORMAÇÃO NO DESEMPENHO FINANCEIRO DAS INDÚSTRIAS BRASILEIRAS}

a) Buscar medidas de avaliação por tipos de investimento em TI, visando compreender como os investimentos em TI podem resultar em capacidades de TI que, por sua vez, podem impactar no desempenho dos negócios;

b) Utilizar dummies de tempo nas regressões, visando mitigar os resultados apurados e possíveis interferências no desempenho; e

c) Adotar o modelo utilizado nesta pesquisa com a associação de análise de clusters (AC), para verificar se há diferenças significativas na forma como cada agrupamento mostra a relação dos GITIs nas variáveis de desempenho financeiro.

\section{REFERÊNCIAS}

ALBERTIN, A. L. Administração de informática - funções e fatores críticos de sucesso. $6^{\text {a }}$. Ed. São Paulo: Atlas, 2009.

ALBERTIN, A. L.; ALBERTIN, R. M. Tecnologia de Informação e Desempenho Empresarial: as dimensões de seu uso e sua relação com os benefícios de negócios. $2^{a}$. Ed. São Paulo: Atlas, 2009.

AL-SHEHAB, A.J., HUGHES, R.T.; WINSTANLEY, G. Modeling risks in IS/IT projects through causal and cognitive mapping. Electronic Journal of Information Systems Evaluation, v. 8, n. 1, p. 1$10,2005$.

ANDERSON, M. C., BANKER, R. D.; RAVINDRAN, S. Value Implications of Investments in Information Technology, Management Science, v. 52, n. 9, p. 1359-1376, 2006.

ARAL, S.; WEILL, P. IT assets, organizational capabilities, and firm performance: How resource allocations and organizational differences explain performance variation. Organization Science. v. 18, n. 5, p.763-780, 2007.

ARELlANO, M. Panel data econometrics - Advanced texts in econometrics. Oxford. Oxford University Press, 2003.

ARELLANO, M.; BOND, S. Some tests of specification for panel data: Monte Carlo evidence and an application to employment equations. Review of Economic Studies, v.58, n. 2, p.277-297, 1991.

BANNISTER, F.; BERGHOUT, E.W., GRIFFITHS, P.; REMENYI, D., Tracing the eclectic (or maybe even chaotic) nature of ICT evaluation, Proceedings of the 13th European Conference on Information Technology Evaluation, Academic conferences Ltd, 2006.

BANNISTER, F.; McCABE, P.; REMENYI, D. How much did we really pay for that? - the awkward problem of Information Technology costs. Electronic Journal of Information Systems Evaluation, v. 5, n. 1, p. 1-20, 2002.

REAd | Porto Alegre - Edição 83 - N 1 - janeiro/abril 2016 - p. 134-165 


\section{Luci Longo \& Fernando De Souza Meirelles}

BEASLEY, M.; BRADFORD, M.; DEHNING, B. The value impact of strategic intent on firms engaged in information systems outsourcing. International Journal of Accounting Information Systems, v. 10, n.2, p. 79-96, 2009.

CARCARY, Marian. The Evaluation of ICT Investment Performance in terms of its Functional Deployment. A Study of Organisational Ability to Leverage Advantage from the Banner MIS in Institutes of Technology in Ireland. Thesis Doctorate Limerick Institute of Technology, 2008.

CRESWELL, J.W. Research design: qualitative, quantitative, and mixed methods approaches. 3th Ed. Los Angeles. SAGE Publications, Inc., 2009.

CVM - Comissão de Valores Mobiliários, Instrução Normativa, IN-CVM N. 527, de 04 de outubro de 2012, Disponível em: http://www.cvm.gov.br/asp/cvmwww/atos/Atos

CVM - Comissão de Valores Mobiliários, Instrução Normativa, Instrução CVM n. 457/07, de 13 de julho de 2007, Disponível em: http://www.cvm.gov.br/asp/cvmwww/

DEHNING, B.; RICHARDSON, V.J. Returns on investments in information technology: A research synthesis. Journal of Information Systems, v.16, n.1, p.7-30, 2002.

DEHNING, B.; RICHARDSON, V.J.; ZMUD, R.W. The financial performance effects of IT-based supply chain management systems in manufacturing firms. Journal of Operations Management, v. 25, n. 4, p. 806-824, 2007.

DEVARAJ, S.; KOHLI, R. Information technology payoff in the health-care industry: A longitudinal study. Journal of Management Information Systems. v. 16, n.4, p. 41-67, 2000.

DEVARAJ, S.; KOHLI, R; . Performance Impacts of Information Technology: Is Actual Usage the Missing Link? Management Science, v. 49, n. 3, p. 273-289, 2003.

DUNN, K.; KOHLBECK, M.; MAGILKE, M. Future profitability, operating cash flows and market valuations associated with offshoring arrangements of technology jobs. Journal of Information Systems, v. 23, n. 2, p. 25-48, 2009.

FARIA, F.A.; MAÇADA, A.C.G. Impacto dos investimentos em TI no resultado operacional dos bancos brasileiros. Revista de Administração de Empresas RAE. São Paulo, v. 51, n. 5, Set/Out, 2011.

FLYVBJERG, B.; BUDZIER, A. Why Your IT Project May be Riskier Than You Think. Harvard Business Review, p. 23-25, September 2011.

GARTNER, I.R.; ZWICKER, R.; RODDER, W. Investimentos em tecnologia de informação e impactos na produtividade empresarial: uma análise à luz do paradoxo da produtividade. RAC, v.13, p. 391-409, 2009.

GHONEIM, A.; IRANI, Z.; SAHRAOUI, S. European Journal of Information Systems 20, 303-307 (May 2011). Disponível em: http://www.palgravejournals.com/ejis/journal/v20/n3/fig_tab/ejis20116t1.html, Acessado em: 15 de janeiro de 2012.

REAd | Porto Alegre - Edição 83 - № 1 - janeiro/abril 2016 - p. 134-165 


\section{IMPACTO DOS INVESTIMENTOS EM TECNOLOGIA DE INFORMAÇÃO NO DESEMPENHO FINANCEIRO DAS INDÚSTRIAS BRASILEIRAS}

HAIR, J.F.Jr; BLACK, W.C.; BABIN, B.J.; ANDERSON, R.E. Multivariate Data Analysis, 7th Ed. Prentice Hall, 2010, 785 p.

HAIR, J.F.Jr; BLACK,W.C.; BABIN, B.J.; ANDERSON, R.E.; TATHAM, R.L. Análise multivariada de dados. 6.Ed. Porto Alegre: Bookman, 2009, 688 p.

HENDERSON, C.; KOBELSKY, K.; RICHARDSON, V. J.; SMITH, R. E. The relevance of information technology expenditures. Journal of Information Systems, v.24, n.2, p.39-78, 2010.

HENDERSON, J. ; VENKATRAMAN, N. Strategic Alignment: Leveraging Information Technology for Transforming Organizations. IBM Systems Journal, v.32, n.1, 1993.

HITT, L. M.; BRYNJOLFSSON, E. Productivity, Business Profitability, and Consumer Surplus: Three Different Measures of Information Technology Value, MIS Quarterly, v.20, n. 2, p. 121-142, 1996.

HU, Q.; PLANT, R. An empirical study of the causal relationship between IT investment and firm performance. Information Resources Management Journal, 17, (1), 37-62, 2001.

IRANI Z.; THEMISTOCLEOUS, M.; LOVE, P.E.D. The Impact of Enterprise Application Integration on Information System Lifecycles, Information \& Management, v. 42, n.2, p. 177-188, 2003.

IRANI, Z.; LOVE, P.E.D. Developing a frame of reference for ex-ante IT/IS investment evaluation. European Journal of Information Systems, n.11, p.74-82, 2002.

KEARNS, G. S. e SABHERWAL, R. - Strategic Alignment between Business and Information Technology: a Knowledge-Based View of Behaviors, Outcome and Consequences. Journal of Management Information Systems, v.23, n.3, p.129-162, 2006.

KOBELSKY, K.; RICHARDSON; V. J.; SMITH, R. E.; ZMUD, R.W. Determinants and consequences of firm information technology budgets. The Accounting Review, v. 83, n.957-996, 2008.

KOHLI, R.; GROVER, V. Business Value of IT: An Essay on Expanding Research Directions to Keep Up with the Times. Journal of the Association for Information Systems, v. 9, n.1, p. 23-39, 2008.

KOHLI, R; DEVARAJ, S. Measuring information technology payoff: a meta analysis of structural variables in firm-level empirical research. Information Systems Research, v. 14, n. 2, p. 127-146, 2003.

KOHLI, R; DEVARAJ, S.; OW, TT. Does information technology investment influence a firm's market value? A case of non-publicly traded healthcare firms. MIS Quarterly. v. 36, n. 4, p. 11451163, 2012.

LAUDON, K.C.; LAUDON, J.P. Sistemas de informação gerenciais. $7^{\text {a }}$.Ed. São Paulo: Pearson Prentice Hall, 2009.

REAd | Porto Alegre - Edição 83 - Nº 1 - janeiro/abril 2016 - p. 134-165 


\section{Luci Longo \& Fernando De Souza Meirelles}

LEE, S.; KIM, S. A lag effect of IT investment on firm performance. Information Resources Management Journal, v. 19, n. 1, p. 43-69, 2006.

LIM, J.H.; DEHNING, B.; RICHARDSON, V.J.; SMITH, R.E. A Meta-Analysis of the Effects of IT Investment on Firm Financial Performance. Journal of Information Systems. v. 25, n.2, p. 145-169, 2011.

LONGO, Luci. Impacto dos Investimentos em Tecnologia de Informação no Desempenho das Indútrias Brasileiras. Tese de Doutorado em Administração de Empresas. Fundação Getulio Vargas (FGV-EAESP), São Paulo, 2014, 221p.

LOVEMAN, G.W. An assessment of productivity impact on information technologies. In: Information technology and the corporation of the 1990s: Research Studies, ALLEN, T.J.; MORTON, M.S. (eds), Oxford University Press, New York, NY, p. 84-110, 1994.

LUCAS, H.Jr. Information technology and the productivity paradox: assessing the value of investing in IT. New York Oxford, Oxford University Press, 1999.

LUFTMAN, J. Assessing Business-IT Alignment Maturity. Communications of AIS, v.4, Dec. 2000.

LUNARDI, G. L. Um Estudo Empírico e Analítico do Impacto da Governança de TI no Desempenho Organizacional. 201f. Tese (Doutorado em Administração) - Universidade Federal do Rio Grande do Sul, Porto Alegre, 2008.

LUNARDI, G.L.; BECKER, J.L; MAÇADA, A.C.G. Um estudo empírico do impacto da governança de TI no desempenho organizacional. Produção: FURG-RS, v. 22, n. 3, p. 612-624, 2012.

MAÇADA, A. C. G.; BECKER, J. L.; LUNARDI, G. L. Efetividade de Conversão dos Investimentos em TI na Eficiência dos Bancos Brasileiros. Revista de Administração Contemporânea, Rio de Janeiro, v. 9, n. 1, p. 9-33, 2005.

MAÇADA, A.C.Gastaud. Impacto dos investimentos em TI nas variáveis estratégicas e na eficiência dos bancos brasileiros. Tese de Doutorado em Administração de Empresas, da Universidade Federal do Rio do Sul (PPGA/UFRGS). Porto Alegre, 2001.

MAHMOOD, M.; MANN, G. Measuring the Organizational Impact of Information Technology Investment: an exploratory study. Journal of Management Information Systems, Walthan, v.10, n.1, p. 97-122, 1993.

MAHMOOD, M.A.; MANN, G.J. Information Technology Investments and Organizational Productivity and Performance: An Empirical Investigation. Journal of Organizational Computing Electronic Commerce. v. 15, n. 3, p.185-202, 2005.

MAIZLISH, B.; HANDLER, R. IT portfolio management step-by-step. step. John Wiley and Sons, 2005.

MARQUES, J. A.V.C.; CARNEIRO JR, J.B.A.; KUHL, C.A. Análise Financeira das Empresas. Rio de Janeiro: Freitas Bastos, 2008.

REAd | Porto Alegre - Edição 83 - № 1 - janeiro/abril 2016 - p. 134-165 


\section{IMPACTO DOS INVESTIMENTOS EM TECNOLOGIA DE INFORMAÇÃO NO DESEMPENHO FINANCEIRO DAS INDÚSTRIAS BRASILEIRAS}

MASLI, A.; RICHARDSON, V. J.; PETERS, G.; SANCHEZ,J.M. Examining the potential benefits of internal control monitoring technology. The Accounting Review, v.85, n.3, p. 1001-1034, 2010.

MASLI, A.; RICHARDSON, V. J.; SANCHEZ, J. M.; SMITH, R. Returns to IT excellence: Evidence from financial performance around information technology excellence awards. International Journal of Accounting Information Systems, v. 12, n. 3, p. 189-205, 2011.

MATARAZZO, Dante Carmine. Análise Financeira de Balanços: abordagem gerencial. - 7. Ed. - São Paulo: Atlas, 2010.

McKEEN, J.D.; SMITH, H.; PARENT, M. Na integrative research approach to assess the business value of information technology. In: Mahmood, M.A. e Szewcak, E.J. Mensuring Information Technology Investement Payoff: Contemporary Approaches. Idea Group Publishing, Hershey, USA, 1999.

MEIRELLES, F. S. Informática - Novas Aplicações com Microcomputadores. São Paulo: McGraw Hill, 1988.

MEIRELLES, F. S. ; MORAES, G. H. S. M. ; LONGO, L. . Indicadores do Uso de Tecnologia de Informação como suporte à Governança de Tecnologia de Informação: Estudos de Casos em Educação. In: XIII SEMEAD Seminários em Administração FEA/USP, 2010, São Paulo - SP. International Conference on Information Systems and Technology Management. São Paulo, v. 1. p.1$15,2010$.

MEIRELlES, F. S. Administração de Recursos de Informática. 1.ed. Pesquisa Anual. São Paulo: Centro de Tecnologia da Informação Aplicada - CIA, FGV-EAESP, 1985.

MEIRELLES, F. S. Administração de Recursos de Informática. 26. ed. Pesquisa Anual. São Paulo: Centro de Tecnologia da Informação Aplicada - CIA, FGV-EAESP, 2015.

MEIRELLES, F. S. Informática - Novas Aplicações com Microcomputadores. São Paulo: McGraw Hill / Makron Books / Pearson Education, 2008.

MENON, N. M.; LEE, B.; ELDENBURG, L. Productivity of Information Systems in the Healthcare Industry. Information Systems Research. v. 11, n.1, p. 83-92, 2000.

MITHAS, S.; TAFTI, A.; BARDHAN, I.; GOH, J. M. Information Technology and Firm Profitability: Mechanisms and Empirical Evidence. MIS Quarterly. v. 36, n. 1, p. 205-224, 2012.

NICOLAOU, A. I. Firm performance effects in relation to the implementation and use of enterprise resource planning systems. Journal of Information Systems. v.18, n.2, p. 79-105, 2004.

O’BRIEN,J.A.; MARAKAS, G.M. Administração de Sistemas de Informação. 15ª .Ed.São Paulo: McGrawHill, 2013, 590p.

PAN, G.S.C.; PAN, S.L.; FLYNN, D. De-escalation of commitment to Information Systems projects: a process perspective. Journal of Strategic Information Systems, v. 13, p. 247-270, 2004.

REAd | Porto Alegre - Edição 83 - N 1 - janeiro/abril 2016 - p. 134-165 


\section{Luci Longo \& Fernando De Souza Meirelles}

PARENTE, S. T; VAN HORN, R. L. The Value of Hospital Investment in Information Technology in For-Profit and Not-for-Profit Hospitals. Health Care Financing Review. v. 28, n. 2, p. 31-43, 2007.

REMENYI, D. The elusive nature of delivering benefits from IT investment.Electronic Journal of Information Systems Evaluation, v. 3, n.1, 2000.

REMENYI, D. IT investment making a business case. Butterworth-Heinemann. Oxford, 1999.

REMENYI, D., BANNISTER, F.; MONEY, A. The effective measurement and management of ICT costs and benefits, 3. Ed. Elsevier CIMA Publishing, Oxford, 2007.

REMENYI, D.; GRIFFITHS, P.D.R.; DINIZ, E.H. The manager in the field and Information and Communications Technology success. In (Ed. D. Remenyi), Proceedings of the 11th European Conference on Information Technology Evaluation, p. 359-370. Amsterdam, The Netherlands, 11th12th November, Academic Conferences, Reading, 2004.

SEDDON, P.B.; CALVERT, C.; YANG, S. A multi-project model of key factors affecting organizational benefits from enterprise systems. MIS Quarterly, v. 34, n. 2, p. 305-328, 2010.

SHIN, N. The impact of information technology on the financial performance of diversified firms. Decision Support Systems, v. 41, n. 4, p. 698-707, 2006.

STRASSMANN, P. The squandered computer, Information Economics Press, New Canaan, 1997.

TINGLING, P.; PARENT, M. An exploration of enterprise technology selection and evaluation. Journal of Strategic Information Systems, v. 13, p. 329-354, 2004.

TURBAN, E.; RAINER, J.R.K.; POTTER, R.E. Administração de tecnologia da informação - teoria e prática. Rio de Janeiro: Campos, Trad. 2. ed. Americana, 2003, 598p.

WEILL, P. The relationship between investiment in information technology and firm performance in the manufacturing sector. PhD. Thesis, Stern School of Business, New York University, 1989.

WEILL, P. The relationship between investment in information technology and firm performance: A study of the valve manufacturing sector. Information Systems Research, v. 3, n. 4, p. 307-333, 1992.

WEILL, P.; ARAL, S. Generating premium returns on your IT investments. MIT Sloan Management Review. v. 47, n. 2, p. 39-48, 2006.

WEILL, P.; BROADBENT, M. Four views of IT infrastructure: Implications for IT investments. In: L. P. Willcocks and S. Lester (eds.), Beyond the IT Productivity Paradox. New York, NT: John Wiley \& Sons, 335-360, 1999.

WEILL, P.; BROADBENT, M. Leavering the new infrastructure: how market leaders capitalize on IT. Boston: Harvard Business Scholl Press, 1998.

WEILL, P.; ROSS, J. A matrix approach to designing IT governance. Sloan Management Review, v. 46, n. 2, p. 26-34, 2005.

REAd | Porto Alegre - Edição 83 - N 1 - janeiro/abril 2016 - p. 134-165 


\section{IMPACTO DOS INVESTIMENTOS EM TECNOLOGIA DE INFORMAÇÃO NO DESEMPENHO FINANCEIRO DAS INDÚSTRIAS BRASILEIRAS}

WEILL, P.; ROSS, J.W. IT Governance: how top performers manage IT decision rights for superior results. Boston: Harvard Business School Press, 2004.

WEILL, P; ROSS, J. W. Governança de TI, Tecnologia de Informação. São Paulo, Ed. M. Books do Brasil, 2006.

WIEDER, B.; BOOTH, P.; MATOLCSY, Z.P.; OSSIMITS, Z. P. , M.L.The impact of ERP systems on firm and business process performance, Journal of Enterprise Information Management, v. 19. n.1, p. 13-29, 2006.

WOOLDRIDGE, J.M. Econometric Analysis of Cross Section and Panel Data. Cambridge, MA Massachusetts Institute Technology-MIT Press, 2002.

WOOLDRIDGE, J.M. Econometric Analysis of Cross Section and Panel Data. Cambridge, MA Massachusetts Institute Technology-MIT Press, 2010.

Apêndice A:

Medidas-resumo das variáveis

\begin{tabular}{|c|c|c|c|c|c|}
\hline $\begin{array}{l}\text { Va } \\
\text { Riáveis }\end{array}$ & Média & $\begin{array}{c}\text { Desvio } \\
\text { Padrão } \\
\end{array}$ & Mínimo & Máximo & $\mathbf{N}$ \\
\hline \multicolumn{6}{|l|}{ ROP } \\
\hline Total & 0,094 & 0,243 & $-4,431$ & 2,065 & 686 \\
\hline Entre & & 0,113 & $-0,393$ & 0,309 & 63 \\
\hline Dentro & & 0,215 & $-3,943$ & 1,927 & 10,89 \\
\hline \multicolumn{6}{|l|}{ CustOp } \\
\hline Total & 0,183 & 0,1 & 0,027 & 0,782 & 686 \\
\hline Entre & & 0,093 & 0,039 & 0,458 & 63 \\
\hline Dentro & & 0,039 & $-0,004$ & 0,507 & 10,89 \\
\hline \multicolumn{6}{|l|}{ ROA } \\
\hline Total & 0,008 & 0,235 & $-3,274$ & 1,847 & 686 \\
\hline Entre & & 0,121 & $-0,378$ & 0,282 & 63 \\
\hline Dentro & & 0,202 & $-2,919$ & 2,065 & 10,89 \\
\hline \multicolumn{6}{|l|}{ LiqC } \\
\hline Total & 1,888 & 1,434 & 0,1 & 13 & 686 \\
\hline Entre & & 1,166 & 0,155 & 6,027 & 63 \\
\hline Dentro & & 0,867 & $-2,939$ & 9,561 & 10,89 \\
\hline \multicolumn{6}{|c|}{ Giro Ativo } \\
\hline Total & 0,909 & 0,457 & 0,012 & 3,517 & 686 \\
\hline Entre & & 0,366 & 0,022 & 2,143 & 63 \\
\hline Dentro & & 0,278 & $-0,076$ & 3,476 & 10,89 \\
\hline \multicolumn{6}{|l|}{ ROE } \\
\hline Total & 0,058 & 1,196 & $-17,398$ & 7,615 & 686 \\
\hline Entre & & 0,591 & $-4,123$ & 0,837 & 63 \\
\hline Dentro & & 1,04 & $-13,217$ & 7,014 & 10,89 \\
\hline \multicolumn{6}{|c|}{ Capital Giro } \\
\hline Total & 0,064 & 0,494 & $-3,568$ & 0,785 & 686 \\
\hline Entre & & 0,445 & $-2,533$ & 0,71 & 63 \\
\hline Dentro & & 0,218 & $-1,128$ & 1,798 & 10,89 \\
\hline \multicolumn{6}{|l|}{ IGTI } \\
\hline Total & 0,016 & 0,014 & 0,001 & 0,09 & 686 \\
\hline Entre & & 0,013 & 0,004 & 0,084 & 63 \\
\hline Dentro & & 0,004 & $-0,007$ & 0,034 & 10,89 \\
\hline
\end{tabular}

REAd | Porto Alegre - Edição 83 - Nº 1 - janeiro/abril 2016 - p. 134-165 
Luci Longo \& Fernando De Souza Meirelles

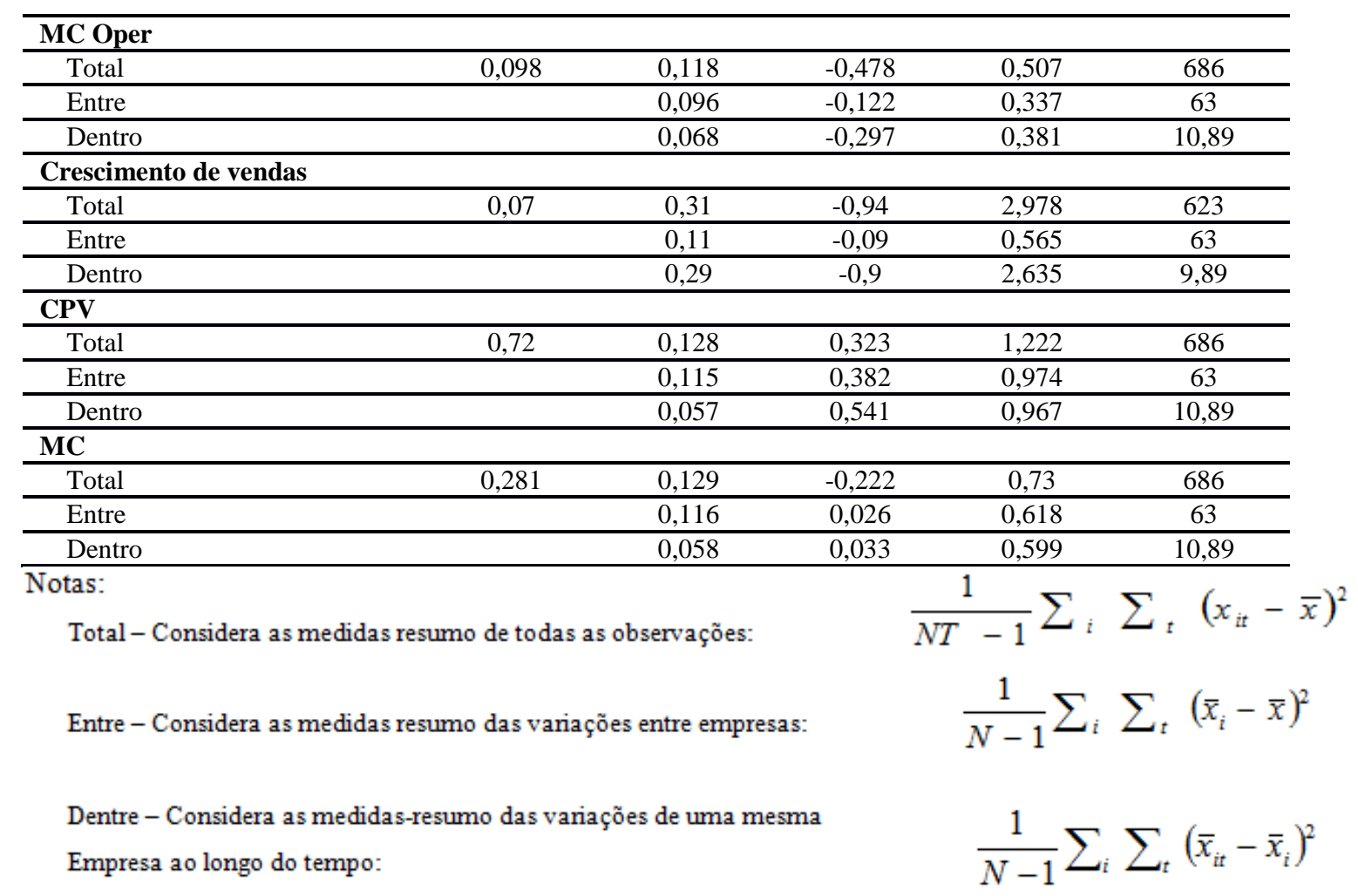

REAd | Porto Alegre - Edição 83 - N 1 - janeiro/abril 2016 - p. 134-165 